Portland State University

PDXScholar

Spring 1-1-2012

\title{
Exploring Ethnic Differences in the Predictors and Outcomes of Academic Engagement During Middle School
}

Robin Margarett Johnson

Portland State University

Follow this and additional works at: https://pdxscholar.library.pdx.edu/open_access_etds

Part of the Bilingual, Multilingual, and Multicultural Education Commons, and the Educational Sociology Commons

Let us know how access to this document benefits you.

\section{Recommended Citation}

Johnson, Robin Margarett, "Exploring Ethnic Differences in the Predictors and Outcomes of Academic Engagement During Middle School" (2012). Dissertations and Theses. Paper 577.

https://doi.org/10.15760/etd.577

This Thesis is brought to you for free and open access. It has been accepted for inclusion in Dissertations and Theses by an authorized administrator of PDXScholar. Please contact us if we can make this document more accessible: pdxscholar@pdx.edu. 
Exploring Ethnic Differences in the Predictors and Outcomes of Academic Engagement During Middle School

$$
\text { by }
$$

\section{Robin Margarett Johnson}

A thesis submitted in partial fulfillment of the requirements for the degree of

\section{Master of Science}

in

Psychology

Thesis committee:

Ellen Skinner, Chair

Lorraine Escribano

Dalton Miller-Jones

Thomas Kindermann

Portland State University

2012 
Abstract

Guided by a motivational framework derived from self-determination theory, a study was conducted to examine the role of academic engagement in helping to explain and ameliorate ethnic differences in school achievement. Building on decades of research that documents both the importance of engagement to learning in European American students as well as its malleability, this study relied on an ethnically diverse sample of 6th and 7th grade students to examine three questions (1) Are achievement differences across ethnic groups due to differences in engagement? (2) Does engagement predict achievement similarly or differently across ethnic groups? and (3) Are the predictors of engagement suggested by the motivational model the same or different for students from different ethnic groups? Participants were 194 African-American, Hispanic/Latino/a, Asian/Pacific Islander, and European American middle school students who provided information about their engagement, self-system processes (SSPs) of relatedness, competence, and autonomy, and their experiences with teachers in school; information about students' cumulative achievement (GPA) was extracted from school records. First, analyses revealed few ethnic differences in achievement (only Asian/Pacific Islander students' levels of achievement were higher than students from other ethnic groups), and no ethnic differences in engagement. In analyses designed to examine if controlling for variations in engagement would cause achievement differences between ethnic groups to disappear, a test of the simple main effects demonstrated that ethnic differences in achievement were found only at the lowest level of engagement (again Asian/Pacific Islander students outperformed all other student groups). However, at medium and high levels of engagement, there were no significant differences in achievement across the 
four ethnic groups. Second, analyses designed to examine whether engagement predicts achievement differently across ethnic groups, revealed that although engagement was an important predictor of achievement for all students, it was even more important for nonEuropean American (compared to European-American) students. Third, analyses designed to examine whether potential facilitators (SSPs and contextual constructs) predicted students' engagement similarly or differently across ethnic groups revealed no group differences: All predictors were positively and significantly associated with engagement for students from all four ethnic groups. These findings are considered in the context of the study's strengths and limitations and the larger literatures on engagement and achievement in ethnic minority students. A important implication of the current study is that with a more comprehensive understanding of how to support the engagement of students from ethnic minority backgrounds, schools and teachers will be better equipped to address the engagement gap, and in so doing also eliminate the achievement gap. 
With deep appreciation and joy I lovingly dedicate this thesis to my dad who has consistently pushed and challenged me to earn and complete this degree. Without his resolute persistence of what I was capable of I may not have crossed this finish line. Daddy, thank you for your love and faith in me. I love you so very much. 
Acknowledgements

I would like to first acknowledge my two graduate school advisors, Ellen Skinner and Dalton Miller-Jones. Dalton, from the time I came into your from office as an senior undergraduate student you have been a source of support and encouragement. I am so grateful for all you've taught me through this journey. Ellen, your timely intervention with so fitting of a research project targeting student engagement levels was nothing short of a miracle. Over the last year and a half I have benefitted so much from your gracious tutelage and unwavering belief in my ability to complete this project despite the barrage of hurdles to be jumped. For all you have done I am so appreciative.

Secondly, I would like to thank the rest of my thesis committee, Lorraine Escribano and Thomas Kindermann, for their time and commitment to helping me finish this project. Additionally I'd like to thank Una Chi for her tutoring and moral support, both of which were significant for the successful completion of this research project.

Lastly, I would like to extend my heartfelt gratitude to my family and friends who devotedly stood by me during graduate school program. Your love has gotten me through so much during the years. Thank you all for being so amazingly wonderful! 
Table of Contents

Abstract....................................................................... i

Dedication.................................................................. ii

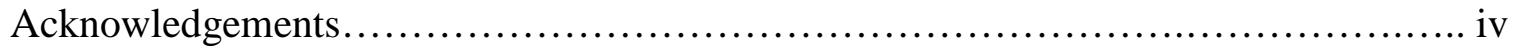

List of Tables....................................................................... vi

List of Figures............................................................ vii

Chapter 1

Introduction................................................................... 1

Chapter 2

Current Study............................................................. 34

Chapter 3

Research Design \& Method.................................................. 42

Chapter 4

Results........................................................................ 51

Chapter 5

Discussion............................................................... 78

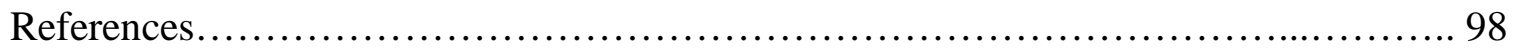


List of Tables

Table 1.1: Summary of Student Engagement of Ethnic Minority Studies....... 9

Table 1.2: Measures of Engagement Used in Studies Under Review............. 14

Table 1.3: Table of Achievement Measures Used in Studies Under Review... 19

Table 1.4: Predictors of Engagement Used in Studies Under Review.......... 27

Table 1.5: Correlations Between Predictors and Engagement in Studies Under Review............................................... 29

Table 3.1: Index of Items by Study Constructs........................... 48

Table 4.1: Summary of Means, Standard Deviations, and Internal Consistencies for each Construct................................. 53

Table 4.2: Intra-Construct Correlations among the Self-System Processes..... 56

Table 4.3: Intra-Construct Correlations among Indicators of School and Teacher Support............................................ 56

Table 4.4: Inter-Construct Correlations Between Engagement, School Supports, Self-System Processes, and GPA........................ 57

Table 4.5: Mean Levels of Achievement for Students from Four Ethnic Groups................................................. 59

Table 4.6: Mean Levels of Engagement for Students from Four Ethnic Groups.................................................. 59

Table 4.7: Mean Level of Engagement by Ethnic Group and Engagement Levels........................................................ 64

Table 4.8: Achievement Means for Each Ethnic Group After Controlling for Engagement............................................ 65

Table 4.9: Multiple Linear Regression Predicting Student Achievement........ 68

Table 4.10: Multiple Linear Regression Predicting Student Achievement for European American versus Non-European American Students....... 70

Table 4:11: Interaction Terms for Engagement and Ethnicity as Unique Predictors for Student Achievement for Each Ethnic Group. 
Table 4.12: Correlations Between Engagement and Achievement by Ethnic

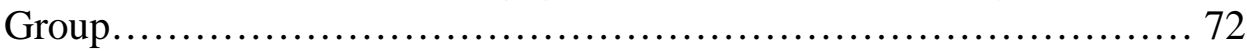

Table 4.13: Interaction Terms Between SSPs and Ethnicity from Multiple Linear Regression Predicting Student Engagement...................... 73

Table 4.14: Multiple Linear Regression Predicting Teacher Support on Student Engagement................................................ 73

Table 4.15: Interaction Terms Between Overall Teacher Support by Ethnic Group from Multiple Linear Regression Predicting Student Engagement....................................................... 76

Table 4.16: Correlations Between Engagement and Self-System and Contextual Predictors for Each Ethnic Group.......................... 77 
List of Figures

Figure 2.1: Self-Determination Model of Engagement...................... 36

Figure 2.2: Model Examining Whether Ethnic Group Differences in

Achievement Are Due to Engagement............................. 40

Figure 2.3: Model Examining Whether Ethnic Group Moderates the Effects of

Engagement on Achievement..................................... 40

Figure 2.4: Model Examining Whether the Predictors of Engagement Are Moderated by Ethnic Group..................................... 41

Figure 4.1: Mean Levels of Student Achievement Across Ethnic Groups....... 60

Figure 4.2: Mean Levels of Student Engagement Across Ethnic Groups........ 61

Figure 4.3: Achievement Mean Levels by Engagement Levels Across

Four Ethnic Groups............................................. 66 


\section{Chapter 1: Introduction}

Chapter 1: Introduction 1

Despite the fact that school success is important for all students, dropout rates are disproportionately high for ethnic minorities and low-income students (National Center for Education Statistics, 2002). Latino/a and African American students have reported dropout rates of approximately 22\% and 11\% compared to 5.8\% for European American students. Additionally, evidence of an ethnic achievement gap (McKinsey Report, 2009), suggests that even those ethnic minority students (e.g., African Americans, Latino/as, Asian Americans, immigrant groups, etc.) who remain in school have an observable disadvantage in our current education system. According to the National Assessment of Education Progress (NAEP, 2007) which administers mathematics and reading assessments to examine long-term trends in the achievement gap, the 23-point African American-European American achievement gap in mathematics (based on a 0-500 point scale) for age nine public school students in 2004 was narrower than in the first assessment in 1978 but not significantly different from the gap in the most recent previous assessment in 1999. The same achievement gap trend was true for the National Center of Education's 26-point gap at the age 13 assessment (NCES, 2009). Past research attempting to explain the achievement gap between ethnic minority students and their European American counterparts has posited deficits in ethnic minority subcultures, for example, in the areas of childrearing, socialization practices, and educational values as possible factors in the educational performance disparities in ethnic minority students (Ogbu, 1985; Spencer, 1985; Ozer, Wolf, \& Kong, 2008).

In recent years educational research has attempted to move away from deficit models as a way to understand the achievement gap in order to focus on more malleable 
Chapter 1: Introduction 2 factors that shape learning, such as student motivation and engagement. This shift in focus is evidenced by the exponential growth of research on academic engagement and its appeal in addressing the needs of our educational system (Skinner \& Pitzer, in press). As the concept of student engagement has come to the forefront of the achievement research, evidence has accumulated that it is a significant predictor of academic success (Fredricks, Blumenfeld, \& Paris, 2004; Sciarra \& Seirup, 2008). Research has found a positive relationship between student engagement levels and their corresponding academic outcomes such as grades and achievement, attendance and graduation, and academic resilience (Connell, Halpbern-Felsher, Clifford, Crichlow, \& Usinger, 1995; Connell, Spencer, \& Aber, 1994). Past research has demonstrated that academically engaged students are more successful in their learning tasks and therefore more successful in achieving more positive academic outcomes within the school environment (Furrer \& Skinner, 2003; Wang \& Holcombe, 2010). In the same vein, studies that have examined disengaged student behaviors (also described as disaffection) have demonstrated that disengagement often leads to poor academic performance and high rates of school dropout (Finn \& Rock, 1997; Retrieved from Alliance For Excellent Education, www.all4ed.org).

If engagement predicts achievement but looks different across ethnic minority groups, then the study of possible ethnic differences in engagement might inform our understanding of the still relevant achievement gap at play in our current education system. By focusing on malleable constructs, such as engagement, to influence students' academic achievement, we could enable teachers and schools to take into consideration ethnic differences of their students and to consequently apply appropriate strategies to 
Chapter 1: Introduction 3

elicit engagement behaviors, and in turn positively impact their students' overall

achievement levels.

\section{Conceptualization of Engagement}

Although there is no single correct definition, engagement is generally understood as a multidimensional construct that includes three separate factors: behaviors, cognitions, and emotions (Fredricks et al., 2004). Behavioral engagement is understood as behavior related to learning; the amount of time put into studying and homework; compliance with school norms and rules; and participation in extracurricular activities (Sciarra \& Seirup, 2008; Skinner, Kindermann, \& Furrer, 2009). Cognitive engagement includes students' effort, motivation, and use of strategies. Emotional engagement refers to students' values, emotions, and interests towards school activities (Fredricks et al., 2004). At the core of many conceptualizations is the idea that engagement with learning opportunities includes eager, constructive, emotionally affirmative, willing, cognitivelyfocused, involvement with academic activities in school (Connell \& Wellborn, 1991; Skinner, Kindermann, Connell, \& Wellborn, 2009).

Consequences of Engagement

Past research has shown a positive relationship between students' cognitive engagement and academic achievement outcomes (Boekart, Pintruch, \& Zeidner, 2000) as well as a positive relationship between behavioral engagement and students' academic achievement outcomes (Marks, 2000) regardless of students' ethnic background. This work has shown that students who actively engage with their schoolwork have the perspective that academics are important and also demonstrates that students who are in compliance with school behavioral norms perform better in the school environment 
Chapter 1: Introduction 4

(Wang \& Holcombe, 2010). "Research shows that a lack of student engagement is predictive of dropping out even after controlling for academic achievement and student background,” (Retrieved from Alliance For Excellent Education, www.all4ed.org). Previous studies have also suggested that emotional engagement has been a shielding mechanism whose protective components help students to stay in school (Skinner \& Pitzer, in press). It is through academic engagement that a student is able to interact with the learning material in a way that enhances the absorption of material/subject being taught (Skinner, Furrer, Marchand, \& Kindermann, 2008). Therefore, if a student's academic engagement levels were low, their diminished interaction with the material would be less effective for true learning to take place.

\section{Predictors of Engagement}

Given its centrality as a predictor of learning, achievement, and school completion research has focused on understanding the predictors and contextual factors that influence (enhance or detract from) engagement. Predictors to engagement have been found to be not only salient but also plastic and responsive to transactional interactions between both the individual and the learning environment (Skinner \& Belmont, 1993). Past research has encompassed a wide-range of predictors of engagement. A majority of these predictors fall under different umbrella-constructs such as context, self, or academic outcomes.

A more complete understanding of the predictors of engagement is necessary in order to effectively implement comprehensive interventions designed to elicit higher rates of academic engagement for students. For example, sense of belonging has also been shown to positively influence student engagement (Fine, 1991; Jennings, 2003; Voelkel, 
Chapter 1: Introduction 5 1997). In order for a student to have a sense of belonging in their school environment there is a need for there to be a level of involvement on the students' part (Connell \& Wellborn, 1990). In other words, if a student feels they are a part of and welcome in the school environment they will feel more inclined to stay there and have more of an opportunity to be academically engaged with the school/classroom environment (Woolley \& Bowen, 2007). Perhaps most important it the relationships students build with their teachers and peers at school seems to provide a layer of support that helps bolster students’ individual school engagement (Fredricks et al., 2004).

Rationale for Literature Review

Most past research has examined school engagement and its effect on academic achievement for European American middle class students. These studies have shown that for European American students all three dimensions of engagement (behavioral, emotional, and cognitive) are significant in influencing students' academic achievement (Fredricks et al., 2004; Skinner, Kindermann, \& Furrer, 2009). While there are a few studies that have looked at ethnic group differences in school engagement, it is still an area where many questions remain unanswered. Given the ways in which our public school system is diversifying, it is becoming increasingly important to examine whether engagement impacts achievement of ethnic minorities the same way it does for the European American counterparts. The study of predictors of engagement for students from different ethnic groups also might inform our interventions to reduce the achievement gap. Understanding the ways in which academic achievement can be influenced through malleable factors (i.e. teacher-student relationships) is a vein of 
Chapter 1: Introduction 6

questioning that could stimulate efforts for positive changes to be made for students regardless of their ethnic group membership.

As a backdrop to conducting research that examines the role of engagement in contributing to the achievement gap for students from different ethnic groups, a literature review was conducted which focuses on three kinds of studies. First, in order to discern whether there is evidence that an "engagement gap" exists that parallels the achievement gap, studies were reviewed that examined comparisons of engagement components and possible differences as a function of ethnic group membership. If engagement contributes to the achievement gaps, such parallel differences in engagement would be expected.

Second, studies were reviewed that examined the effects of engagement on achievement for students who were from ethnic minority groups. For engagement to play a role in creating the achievement gap, engagement must have the same kind of impact on achievement for children from ethnic minorities as has been found for European American middle class children. Third, studies were reviewed that examined what predictors of engagement were influential in promoting the engagement of ethnic minority students and whether these predictors differ in the significance from those for European American middle class children. If schools have the potential to reduce the achievement gap by promoting the engagement of students from ethnic minority groups, then it would be important to discover the primary predictors of engagement for students from ethnic minority backgrounds, and whether these predictors differ from those for European American middle class children. Hence, studies were reviewed which 
Chapter 1: Introduction 7

examined the connections between features of the school context and engagement for children from ethnic minority groups.

\section{Literature Review}

Thirteen articles were retrieved that examined engagement and predictors of engagement in children from ethnic minority families presented in Table 1.1. Six of the journal articles focused on homogeneous samples of children from African American families. One of the journal articles focused on a homogenous sample of youth from Latino/a families. All of these six studies reviewed with homogeneous samples focused on middle and high school age groups.

The six remaining studies used heterogeneous samples with which to draw their analysis. Two of the studies reviewed had samples with comparisons from three minority groups. One study differentiated their groups as African American, European American, and "Other." This study focused on $7^{\text {th }}$ and $8^{\text {th }}$ grade students. The other study differentiated their groups as African American, European American, and Hispanic. Four of the reviewed articles did comparisons between five different ethnic groups. Minority groups represented were Chinese American, Latino/a, African American, Filipino/a, European American, Native American, Asians, “Other,” Chinese, Dominicans, Central American, Haitians, and Mexicans. These studies examined engagement in middle and high school age students. All four of these studies focused on middle and high school students.

Engagement Measures

Of the 13 studies reviewed, many used selected items from a few various measures to examine engagement while only a handful of studies used complete 
Chapter 1: Introduction 8

instruments to assess student engagement (see Table 1.2). The most commonly used measure of engagement was the Rochester Assessment Package for Schools (RAPS-S; Wellborn \& Connell, 1987), which was used by two of the studies (studies 1b and 4). Other measures of engagement were also examined by five studies by using different preexisting instruments: Intellectual Achievement Responsibility Scale (Crandall, Katkovsky, \& Crandall, 1965); Self-Efficacy Expectations (Wheeler \& Ladd, 1982); School participation, identification, self-regulation strategies (Eccles, Midgley, Cuchanan, Flanagan, Mac Iver, Reuman, \& Widgefield, 1993); Student Engagement Instrument (SEI) (Appleton, Christenson, \& Reschly, 2006); and the School Success Profile (SSP; Suarez-Orozco, Gaytan, Bang, Pakes, O'Conner, \& Rhodes, 2010). Items targeting affect were items selected from Voelkl $(1993,1996,1997)$ were used by one of the studies. A majority of the studies used measures that were not used by anyone else. Of these 13 studies reviewed, three studies didn't state the measures used but rather disclosed the number of items tapping such constructs as behavioral, cognitive, of affective engagement (i.e. "I look forward to learning new things at school" and "I find school exciting”). 
Table 1.1

Summary of Student Engagement of Ethnic Minority Studies

\section{Study}

Connell, J., Spencer, M., Aber, L., (1994)

Sirin, S. \& RogersSirin, L. (2004)

\section{Age/Ethnicity Youth}

African-American students: *Atlanta - 215 students, 10.916.7 years old. *New York 399 students 12-17 years old. *New York City - 360 students, 10.3-16.7 years old.

336 African-American students, 12-19 years old

\section{Measure(s) of Engagement}

Atlanta sample used the Intellectual Achievement Responsibility Scale; New York used the Rochester Assessment Package for Schools; New York City used the Self-Efficacy Expectations

School engagement - nine items reflected sense of belonging (Fine, 1991; Voelkl, 1997) and behaviors in school and activities in class (Fine, 1993)

\section{Engagement}

Predictors

Perceived:

Competence/Efficacy;

Relatedness to Others

Educational

Expectations; Self-

Esteem; Parental

Involvement 
Sirin, S. \& RogersSirin, L. (2005)

Connell, J., HalpernFelsher, B., Clifford, E., Crichlow, W., \& Usinger, P. (1995)

Gutman, L. \& Midgley, C. (2000)

Garcia-Reid, P., Reid, R., Peterson, A. (2005)
499 African-American students, 14-19 years old

433 African-American 7th9th Graders

\section{African American Families, 6th-8th Graders}

226 Latino, 6th-8th Grade students 9-item index to measure both

N/A

affective components

(Voelkl, 1996, 1997),

behavioral components (Finn

1993) and the students'

perceptions of their

educational future (Voelkel, 1993; Walker \& Sutherland, 1993)

Rochester Assessment Package for Schools-Student Report (RAPS-S; Wellborn

\& Connell, 1987) 204-items

Academic Self-Efficacy was measured by the Patterns of Adaptive Learning Survey (Midgely, Hicks, Roeser, Urden, Anderman, Kaplan, Arunkumar, \& Middleton, 1997)

Subscale of School Success Profile (SSP) (Bowen \& Richman, 1995)
Competence;

Autonomy; Relatedness

Perceived parental involvement and teacher support

Teacher support, friend support, and parent support 
Smerdon, B. (1999)

Wang, M. \&

Holcombe, R. (2010)

Sciarra, D., Seirup, H., (2008)

Suarez-Orozco, C., Gaytan, F., Bang, H. J., Pakes, J., O'Conner, E., Rhodes, J., (2010)
12,700 African-American, European American, and Asian 10th graders

1046 7th and 8th Grade students; 56\% African American, 23\% EuropeanAmerican; 12\% Other

11388 12th grade students: 115 American Indians, 486 Asians, 1551 African Americans, 1682 Latinos, and 7554 European Americans

40712 years old students: 72 Chinese; 60 Dominicans; 57 Central Americans; 50

Haitians; 70 Mexicans) *all are immigrants
Student report on a composite Not Examined of the three constructs:

Attendance; Preparedness for classwork; Investment

School engagement index (14 Perceptions of School items) - school participation, Environment identification, self-regulation Performance Goal strategies (Eccles et al. 1993) Structure; Mastery of Goal Structure; Support of Autonomy;

Promotion of Discussion; Teacher Social Support

Behavioral (14 items-teacher \& students); Emotional (24 items-teacher \& students); Cognitive (10 items-teacher and students)

7 item report scale focused on behaviors

Not Examined

Family Characteristics; School Characteristics; Student Perceptions of School Violence, and Academic English Proficiency correlations not given 
Woolley, M. \&

Bowen, G. (2007)

Kelly (2008)
7763 Middle School students: 3831 African American; 3707 European American; and 225 Hispanics

1922 Middle School students: White, Hispanic, American Indian, Asian, and Black (percentages not given)

123 7th-8th grade students: 59\% Latino/a, 12\% AfricanAmerican, 9\% AsianAmerican, 1\% NativeAmerican, 20\% multiracial/other
School Success Profile (SSP) Contextual Risk and - School Engagement index - Social Capital Assets 11 items (psychological and behavioral engagement)

Observational data looking at "procedural" vs.

"substantive" participation; Year-end student report asking about amount of time put into homework

11-item General Attitude Toward School subscale of the School Sentiment Index (SSI: Firth \& Narikawa, 1972)

\section{correlations not given}

Student's Level of Initial

Achievement and

Student Social Class:

Educational and

Occupational

Attainment of Parents -

correlations not given

Teacher support, family support, and peer support 
Chapter 1: Introduction 13

Five of the studies examined engagement specifically for homogeneous samples

of African American students, ages ranging from 10- to 19- years old. These studies used a variety of nine different constructs labeled "engagement” to capture student engagement. The surveys or measure items used to capture engagement were Intellectual Achievement Responsibility Scale (Crandall, Katkovsky, \& Crandall, 1965); Rochester Assessment Package for Schools (RAPS-S; Wellborn \& Connell, 1987); Self-Efficacy Expectations (Wheeler \& Ladd, 1982); Behavioral Components of Engagement (Fine, 1993); students perceptions of their educational future (Voelkl, 1993; Walker \& Sutherland, 1993); affective components of engagement (Voelkl, 1996, 1997); and student-report on a composite of the three constructs: attendance; preparedness for classwork; and investment.

\section{Are There Ethnic Differences in Engagement?}

Two out of the 13 studies reviewed looked directly at ethnic group comparisons in school engagement. The first study (Kelly, 2007) used data collected by the National Research Center on English Learning and Achievement (CELA). Observational and survey data was collected from a total of 63 classrooms from two cohorts of teachers in Wisconsin and New York State over a two-year period. Nineteen schools participated in the data collection in 2001-2002, while 57 classrooms located in 23 schools participated in 2002-2003. The participation rate for students across all classrooms was $82.8 \%$, resulting in 2051 students in 117 classrooms. Most analyses relied on 1,922 students with fall achievement data.

In this study, observations were conducted and questionnaires collected from 2051 students across a total of $1177^{\text {th }}$ and $8^{\text {th }}$ grade classrooms. The ethnic groups 
Chapter 1: Introduction 14

represented in their sample were African American, Hispanic, Native American, Asian, and European American students.

Table 1.2

Measures of Engagement Used in Studies Under Review

Measures

Study \#

Intellectual Achievement Responsibility Scale (Crandall, Katkovsky, \& Crandall, 1965)

$1 \mathrm{a}$

Rochester Assessment Package for Schools (RAPS-S) (Wellborn \& Connell, 1987)

1b, 4

Self-Efficacy Expectations (Wheeler \& Ladd, 1982)

$1 \mathrm{c}$

9-items constructed to reflect students' sense of belonging and

behaviors in the classroom

2

Index to measure both affective components (Voelkel, 1996, 1997), behavioral components (Finn 1993) and the students' perceptions of their educational future (Voelkel, 1993; Walker \& Sutherland, 1993)

Student report on a composite of the three constructs: Attendance; Preparedness for classwork; Investment

14-items reporting on school participation, school identification, and use of self-regulation strategies (Eccles, Midgley, Cuchanan, Flanagan, Mac Iver, Reuman, \& Widgefield, 1993)

Behavioral (14 items-teacher \& students)

Emotional (24 items-teacher \& students)

Cognitive (10 items-teacher and students)

7 item report scale focused on behaviors

School Success Profile (SSP) - School Engagement index that represented psychological or behavioral engagement in schooling

Observational data looking at "procedural" vs. "substantive" participation

Scale of student effort

Academic self efficacy taken from Patterns of Adaptive Learning Survey (PALS; Midgley Maehr, hicks, Roeser, Urdan, Anderman, Kaplan, Arunkumar, \& Middleton, 1997)

General Attitude Toward School subscale of the School Sentiment Index (SSI; Frith and Narikawa, 1972)

Three item school engagement subscale of the School Success Profile (SSP; Bowen \& Richman, 1995) 
Chapter 1: Introduction 15 The data collected were classroom observations of students' "procedural participation" and "substantive participation" defined as: (a) procedural participation refers to asking or answering non-authentic, low cognitive level questions, and (b) substantive participation refers to asking or answering either authentic questions, or questions that involve high level thinking, or posing a question with "authentic uptake,” (p. 439). In addition, a yearend survey was administered in which students reported (1) how often they completed reading and writing assignments (using a 7 point scales from "never” to "every time”); (2) how often they revised or rewrote papers (using a 7 point scales from "never" to "every time"); and (3) how much time they spent on English homework each week (on a 7 point scale from "none" to "four hours or more"). These measures were used to create a scale of student effort $(\alpha=.57)$.

Multi-level regression models were used to compare count outcomes across groupings of classrooms. Teacher-student question counts were tallied by low or high SES and further categorized by who initiated the questions and whether or not it was a procedural question or an authentic question. However, findings were presented in ways that proved too difficult to interpret, so they are not summarized in this literature review. According to the researchers, there were no significant differences in the engagement levels of African American, Native American, Asian or Pacific Islander, Latino/a, or European American students. The "strongest conclusion from this study was that "the strongest predictor of engagement within classrooms is not ethnicity or social class, but a student’s level of initial achievement.” (Kelly, 2008, p. 446).

The second study, by Woolley \& Bowen (2007), was conducted with a group of African American, European American, and Hispanic middle school students $(n=7763)$. 
Chapter 1: Introduction 16 Between July 2001 and March 2003, a total of 9,041 middle school students, across 51 schools and five states were administered the School Success Profile (SSP), an 11-item index used to capture psychological and behavioral components of engagement. These schools had contracted with the School of Social Work at the University of North Carolina at Chapel Hill for administration of the SSP. One of the study's goals was to investigate differences by ethnicity; therefore, groups with sample sizes too small for group-level analyses were eliminated from the data set (the groups that were eliminated included Native American/Alaska Native, Asian/Pacific Islander, multiracial, and other). In addition, participants with missing values on indicators needed to calculate the risk, social capital, or school engagement indexes, or on other variables necessary for the analyses, were eliminated. This reduced the sample size to 7,764. As indicators of the at-risk nature of this sample, 58.6\% of students reported receiving free or reduced lunch program, and $22.8 \%$ of the students reported repeating one or more grades.

The SSP had three indices to measure students' school success: the contextual risk index, the social capital assets index, and the school engagement index. The school engagement index contained 11 survey items that represented psychological and behavioral engagement in school. Comparatively, on the school engagement index, European American students reported the highest average level $(M=11.9, S D=2.7)$, which was statistically different from the school engagement of both Hispanic/Latino/a students $(M=10.8, S D=2.9, t=-5.6, p<.000)$ and African American students $(M=$ 11.2, $S D=2.6, t=-11.4, \mathrm{p}<.000$ ), who were not significantly different from each other. Summary 
Chapter 1: Introduction 17

These two studies, while looking at engagement differences across ethnic groups, provided mixed results with made it difficult to come to any concrete conclusions.

\section{Does Engagement Predict Achievement In Ethnic Minority Youth?}

Of the 13 studies reviewed, 10 examined the connection between engagement and achievement. The most commonly used measurements of academic achievement utilized in these studies (see Table 1.3) were GPA and standardized achievement tests scores. Four of the remaining studies used varying standardized test scores: reading and math test scores; math achievement scores; academic English proficiency scores; and CELA achievement scores to capture student achievement levels. These studies had ethnically heterogeneous samples. Two of the studies used other subject combinations to obtain student GPAs to obtain a measure of student achievement levels. Finally, there was the 5-flag Identification System (Cricklow \& Vito, 1989), which is a complex combination of disengagement factors that significantly contribute to the prediction of school departure, and students' GPA for one year in mathematics, science, history or social studies, and English/Language arts.

Homogeneous Samples

Of the six studies with homogeneous samples, all examined the correlation between engagement and achievement measures, in homogeneous samples, although one study with a heterogeneous sample reported correlations between engagement and achievement on five homogeneous subsamples. Of the 25 correlations, 13 involved African American students and all 13 correlations were proven to be positive and significant. 
Chapter 1: Introduction 18 African American students. In a study of African American high school students, Connell, Spencer and Aber (1994) compiled three subsamples of students from Atlanta, New York, and New York City to examine correlations between engagement (three separate measures were used) and positive and negative achievement outcomes (measured as a complex combination of GPA and other outcome variables, see Table 1.2). In a sample of African American 10- to 16- year-olds in Atlanta $(n=215)$, Connell et al., (1994) found correlations between engagement (measured as Intellectual Achievement Responsibility Scale) and achievement (measured as a complex combination of GPA and other outcome variables) of $r=-.28, p<.001$ and $r=.18, p<$ .01 , for negative and positive outcomes respectively. In a sample of African American 12- to 17- year-olds in New York $(n=399)$, Connell et al., (1994) found correlations between engagement (measured using the Rochester Assessment Package for Schools) and achievement (measured as a complex combination of GPA and other outcome variables) of $r=.22, p<.001$ and $r=.23, p<.001$, for negative and positive outcomes respectively. In a sample of African American 10- to 16- year-olds in New York City ( $n$ = 360), Connell et al., (1994) found correlations between engagement (measured as SelfEfficacy Expectations) and achievement (measured as a complex combination of GPA and other outcome 
Table 1.3

Chapter 1: Introduction 19

\begin{tabular}{|l|c|}
\hline \multicolumn{2}{|c|}{ Table of Achievement Measures Used in Studies Under Review } \\
\hline Measures & Study \# \\
\hline $\begin{array}{l}\text { GPA - for one year in mathematics, science, history or social studies, } \\
\text { and English/language arts }\end{array}$ & $3,6,9$ \\
\hline $\begin{array}{l}\text { Negative outcomes - 5-flag Identification System (Cricklow \& Vito, } \\
\text { 1989) -presence and degree of risk in school departure: attendance; } \\
\text { national percentile on standardized math and reading; two of more } \\
\text { core studies were failed in the past year; suspensions; and age of } \\
\text { student being 1+ average student age. }\end{array}$ & 1,4 \\
\hline $\begin{array}{l}\text { Positive outcomes -3-star system (Connell, Spencer, \& Abler, 1994) } \\
\text { - attendance ratio; national percentile on standardized math and } \\
\text { reading; and GPA }\end{array}$ & 1 \\
\hline GPA - for one year in mathematics and English & 2 \\
\hline Standardized test scores in reading and math & 5 \\
\hline Standardized math achievement scores & 7 \\
\hline Academic English proficiency & 8 \\
\hline CELA achievement score & 11 \\
\hline
\end{tabular}

variables) of $r=-.38, p<.001$ and $r=.51, p<.001$, for negative and positive outcomes respectively. In this same study, path coefficients for the whole model (context, self, action, outcomes) across all three samples were run. For negative outcomes, path coefficients from engagement were $\beta=-.24, p<.001, \beta=-.17, p<.01, \beta=-.40, p<$ .001, for Atlanta, New York, and New York City, respectively. For positive outcomes path coefficients from engagement were $\beta=.13, p<.05, \beta=-.18, p<.01, \beta=.55, p<$ .01, for Atlanta, New York, and New York City, respectively.

In a sample of African American 12- to 19- year-olds $(n=336)$, Sirin and RogersSirin (2004) found a correlation between engagement (measured as nine items reflecting a sense of belonging, behaviors in school, and activities in class) and achievement 
Chapter 1: Introduction 20 (measured as GPA for one year in mathematics and English) of $r=.22, p<.001$. In a sample of African American 14- to 19- year-olds ( $n=499)$, Sirin and Rogers-Sirin (2005) found correlations between three facets of engagement (measured as affect, behavior, and students' perceptions of their educational future) and academic performance (measured as GPA for one year in mathematics, science, history or social studies, and English/language arts) of $r=.16, p<.001 ; r=.35, p<.001 ; r=.36, p<.001$ for school identification (affect), participation (behavior) and expectations, respectively. In a sample of African American middle school students ( $n=62$ ), Gutman and Midgely (2000) found correlations between engagement (measured as $6^{\text {th }}$ grade academic self efficacy taken from the Patterns of Adaptive Learning Survey) and achievement (measured as GPA at the end of the school year in core subjects social studies, language arts, math and science in $5^{\text {th }}$ and $6^{\text {th }}$ grade) of $r=.45, p<.01$ and $r=.41, p<.01$ at the end of $5^{\text {th }}$ and $6^{\text {th }}$ grade, respectively.

Heterogeneous Sample Analyzed by Homogeneous Sub-Samples

In a study of multiple ethnic groups, Sciarra and Seirup (2008), reported correlations between engagement and achievement for each ethnic group as heterogeneous subsamples. They calculated correlations between achievement (measured as standardized math achievement scores) and three facets of engagement, namely, behavioral (14-items teacher and student), emotional (24-items teacher and student), and cognitive (10-items teacher and student) engagement, for each of the five ethnic subsample groupings: Native American, Asian American, African American, Latino/a, and European American. 
Chapter 1: Introduction 21

African American students. For the African American subsample $(n=1,551)$, the authors found correlations between engagement and math achievement of $r=.25$, $p<$ $.01 ; r=.08, p<.01 ; r=.19, p<.01$, for behavioral engagement, emotional engagement, and cognitive engagement, respectively.

Native American students. For the Native American subsample $(n=115)$, the authors found correlations between engagement and math achievement of $r=.32$, $p<$ $.01 ; r=.14, n s ; r=.35, p<.01$, for behavioral engagement, emotional engagement, and cognitive engagement, respectively.

Asian American students. For the Asian American subsample $(n=486)$, the authors found correlations between engagement and math achievement of $r=.31, p<$ $.01 ; r=.04, n s ; r=.24, p<.01$, for behavioral engagement, emotional engagement, and cognitive engagement, respectively.

Latino/a students. For the Latino/a subsample $(n=1,682)$, the authors found correlations between engagement and math achievement of $r=.21, p<.01 ; r=.16, p<$ $.01 ; r=.20, p<.01$, for behavioral engagement, emotional engagement, and cognitive engagement, respectively.

European American students. For the European American subsample $(n=7,554)$, the authors found correlations between engagement and math achievement of $r=.34, p<$ $.01 ; r=.17, p<.01 ; r=.29, p<.01$, for behavioral engagement, emotional engagement, and cognitive engagement, respectively.

\section{Heterogeneous Samples}

Three of the seven studies with heterogeneous samples examined whether engagement predicts academic achievement; these studies had ethnic group 
Chapter 1: Introduction 22

representations in their samples with two to six ethnic groups. In a sample of African American, European American, and “Other" $7^{\text {th }}$ to $8^{\text {th }}$ grade students $(n=1046)$, Wang and Holcombe (2010) found correlations between engagement (measured as 14-items capturing school participation, school identification, and use of self-regulation strategies) and achievement (measured as GPA for one year in mathematics, science, history or social studies, and English/language arts) of $r=.17, p<.01, r=.23, p<.01$, and $r=.18$, $p<.01$, for school participation, school identification, and use of self-regulation strategies, respectively.

In the third study with a heterogeneous sample, Suarez-Orozco and colleagues (2010) looked at the relationship between engagement and achievement with a sample of immigrant 12-year old students from Central America, China, Dominic Republic, Haiti, and Mexico $(n=407)$ using latent class growth modeling to identify five groups if students who differed on their trajectories of academic achievement from sixth to twelfth grade. The groups identified were High Achievers who showed consistently high levels of achievement across middle and high school. Precipitous Decliners who showed a steep decline in their achievement levels across middle and high school. Slow Decliners who showed a gradual decline in their achievement levels across middle and high school. Improving who showed a steady increase in achievement levels across middle and high school. Low Achievers who showed consistently low levels of achievement across middle and high school. The odd ratios $(O R)$, provided by this study, showed that for the students with low levels of engagement were more likely to be found among the Precipitous Decliners $(O R=1.32, p<.01)$, Slow Decliners $(O R=1.48, p<.001)$ and Low Achievers $(O R=.1 .70, p<.001)$ than among the High Achievers. In addition, high 
Chapter 1: Introduction 23

levels of engagement were related to greater likelihood of being an Improving Achiever than a Precipitous Decliner $(O R=2.17, p<.01)$.

Summary of Connections Between Engagement and Achievement in Ethnically Diverse Youth

Of the total 13 studies reviewed, eight of these studies (four with homogeneous samples, four with heterogeneous samples) examined the relationship between engagement and achievement. Across these eight studies, there were 10 separate constructs of achievement (the majority being a calculation of GPA) along with 17 constructs of engagement. In total there were 30 correlations between engagement and achievement, 28 of which were positive and significant, while two were found to be not significant. The strongest support for the positive relationship between engagement and achievement were found in the African American samples and subsample, with all 13 correlations showing positive and significant connections between engagement and achievement. The Latino/a subsample had three correlations related to engagement and achievement; all of these correlations were positive and significant. The Native American and Asian American subsamples also had three correlations related to engagement and achievement. For both of these subsamples, however, only two out of the three reported correlations were positive and significant, not significant was emotional engagement (measured as 24-items teacher and student rated).

What Are the Predictors of Engagement in Ethnic Minority Youth?

There were eight studies that examined predictors of engagement. These studies had both homogeneous and heterogeneous samples of ethnic minority children and youth. They consider a wide variety of factors that could shape students' engagement in school. 
Chapter 1: Introduction 24

The 18 different factors they included are presented in Table 1.4 and organized according to three different kids of constructs: (1) “Context” which refers to characteristics of teachers, schools, parents, and peers that can influence how a student becomes engaged in school; and (2) "Self" which refers to self-perceptions and beliefs that influence how a student becomes engaged in school.

The 18 constructs were labeled and measured in a variety of ways, but many of them were attempting to capture similar constructs. The most commonly measured predictor, categorized under context, was teacher support. The summary of findings from the studies about the connections between hypothesized predictors and engagement are presented first for predictors referred to as "context," second for those that are referred to as “self,” and lastly as “academic performance” are presented in Table 1.4.

Homogenous Samples - Context Constructs

Of the 13 studies reviewed, eight studies considered contextual features as predictors of engagement; three of them utilized homogenous samples, two African American homogeneous samples and one Latino/a homogeneous sample.

African American students. In a sample of African American, 12- to 19- year-old students ( $n=336)$, Sirin and Rogers-Sirin (2004) found a correlation between predictors of engagement (measured as parent-adolescent relationships and parent education values) and engagement (measured as nine items reflecting sense of belonging and behaviors in school and activities in class) of $r=.13, p<.05$ and $r=.07, n s$, for parent-adolescent relationships and parent education values, respectively. In a sample of African American middle school students ( $n=62$ ), Gutman and Midgley (2000) found correlations between predictors of engagement (measured as teacher support, parental involvement, and school 
Chapter 1: Introduction 25

belonging) and engagement (measured as academic self efficacy taken from Patterns of Adaptive Learning Survey) of $r=.31, p<.05, r=.07$, ns, and $r=.39, p<.001$, for teacher support, parental involvement, and school belonging, respectively.

Latino/a students. In a sample of Latino/a middle school students $(n=226)$, Garcia-Reid, Reid, and Peterson (2005) found correlations between predictors of engagement (measured as teacher support, friend support, and parent support) and engagement (measured as the School Success Profile) of $r=.35, p<.01, r=.23, p<.01$, and $r=.21, p<.01$ for teacher support, friend support, and parent support, respectively Homogeneous Samples - Self Constructs

There were two studies that examined the relationship between self-construct predictors and engagement. Both studies had homogeneous African American samples. African-American students. In a study of African American high school students, Connell, Spencer and Aber (1994) compiled three subsamples of students from Atlanta, New York, and New York City to examine correlations between predictors of engagement (measured as an aggregated construct of self) and engagement (three separate measures were used). In a sample of African American 10 to 16 year-olds in Atlanta ( $n=215)$, Connell et al., (1994) found a correlation between predictors of engagement (measured as an aggregated self construct) and engagement (measured using the Intellectual Achievement Responsibility Scale) of $r=.57, p<.001$. In a sample of African American 12 to 17 year-olds in New York $(n=399)$, Connell et al., (1994) found a correlation between predictors of engagement (measured as an aggregated self construct) and engagement (measured using the Rochester Assessment Package for Schools) of $r=.31, p<.001$. In a sample of African American 10 to 16 year-olds in New 
Chapter 1: Introduction 26 York City $(n=360)$, Connell et al., (1994) found a correlation between predictors of engagement (measured as an aggregated self construct) and engagement (measured as Self-Efficacy Expectations) of $r=.24, p<.01$.

In a sample of African American 12- to 19- year old students ( $n=336)$, Sirin and Rogers-Sirin (2005) found correlations between predictors of engagement (measured as educational expectations and self-esteem) and engagement (measured as 9-items constructed to reflect students' sense of belonging and behaviors in the classroom) of $r=$ $.31, p<.001$ and $r=.14, p<.01$, for educational expectations and self-esteem, respectively. In a sample of African American $7^{\text {th }}$ to $9^{\text {th }}$ graders $(n=443)$, Connell et al, (1995) found correlations between predictors of engagement (measured as an aggregated self constructs) and engagement (measured using the Rochester Assessment Package for Schools-Student Report) of $r=.50, p<.001$ and $r=.53, p<.001$ for competence/efficacy, for males and females respectively, and $r=.58, p<.001$ and $r=$ $.62, p<.001$ for relatedness to self and others, for males and females, respectively. Heterogeneous Samples - Context Constructs

In a sample of African American, European American, and biracial/other $7^{\text {th }}$ and $8^{\text {th }}$ grade students $(n=1,046)$, Wang and Holcombe (2010) found correlations between predictors of engagement (measured as teacher social support, performance goal structure, mastery goal structure, support of autonomy, and promotion of discussion) and engagement (measured as school participation, school identification, and use of self regulation strategies). For school performance goal structure, correlations with school participation, school identification, and use of self-regulation strategies were $r=-.26, p<$ $.01 ; r=-.38, p<.01$; and $r=.09, p<.01$, respectively. For school mastery goal 
Chapter 1: Introduction 27 structure, correlations with school participation, school identification, and use of selfregulation strategies were $r=.18, p<.01 ; r=.35, p<.01$; and $r=$ $.36, p<.01$, respectively. For support of autonomy, correlations with school participation, school identification, and use of self-regulation strategies were $r=.17, p<$ $.01 ; r=.31, p<.01$; and $r=.29, p<.01$, respectively. For promotion of discussion, correlations with school participation, school identification, and use of self-regulation strategies were $r=-.05, n s ; r=.17$, $p<.01$; and $r=.19, p<.01$ respectively. For teacher social support, correlations with school participation and school identification, and use of self-regulation strategies were $r$ $=.19, p<.01 ; r=.26, p<.01$; and $r=.21, p<.01$, respectively.

Table 1.4

\begin{tabular}{|c|c|c|c|}
\hline \multicolumn{4}{|c|}{ Predictors of Engagement Used in Studies Under Review } \\
\hline & Study & & Study \\
\hline Context & \# & Self & \# \\
\hline School/Classroom/Teacher & & elf-System Processes & \\
\hline Teacher Support & $\begin{array}{c}5,6 \\
13\end{array}$ & $\begin{array}{l}\text { Aggregated Self- } \\
\text { Construct }\end{array}$ & 1 \\
\hline Teacher Social Support & 8 & Autonomy & 4 \\
\hline Support of Autonomy & 8 & Educational Expectations & 2 \\
\hline Promotion of Discussion & 8 & Self-Esteem & 2 \\
\hline Performance Goal Structure & 10 & School Belonging & 5 \\
\hline Mastery Goal Structure & 8 & & \\
\hline \multicolumn{4}{|l|}{ Peers/Friends } \\
\hline Peer Support & 13 & & \\
\hline Friend Support & 6 & & \\
\hline \multicolumn{4}{|l|}{ Family/Parenting } \\
\hline Family Support & 13 & & \\
\hline Parent-Adolescent Relationships & 2 & & \\
\hline Parent Education Values & 2 & & \\
\hline Parent Support & 6 & & \\
\hline Parental Involvement & 5 & & \\
\hline
\end{tabular}


Chapter 1: Introduction 28

In a sample of Latino/a, African American, Asian American, Native American, and biracial/other 12- to15- year-old students ( $n=123)$, Daly and colleagues (2009), found correlations between predictors of engagement (measured as teacher support, family support, and peer support) and engagement (measured as general attitude toward school subscale of the School Sentiment Index; SSI) of $r=.29, p<.01$ and $r=.33, p<$ .01, for teacher support and family support, respectively. However, for this study, peers support as a predictor and student engagement correlations were found to be not significant for, $r=.14$, $n$ s.

Summary of Connections Between Predictors and Engagement in Ethnically Diverse Youth

Of the total 13 studies reviewed, eight of these studies (three with homogenous samples, five with heterogeneous samples) examined the relationship between engagement and its predictors (contextual and self systems). Out of these eight studies 18 constructs of engagement predictors were reported providing 36 total correlations, 31 were found to be positive and significant and four were found to be not significant. There were two studies with homogenous African American samples; together they had a combined total of five correlations for contextual predictors of engagement, three were found to be positive and significant. The one study with a homogeneous Latino/a sample, had three correlations for contextual predictors of engagement, all three were significant. One study with three nested homogeneous African American subsamples had a total of nine correlations for constructs that fell under self predictors of engagement, all nine were reported significant. 
Chapter 1: Introduction 29

Most of the correlations examined were found among the African American samples and sub-samples. Under the umbrella constructs of context and self there were 19 positive and significant correlations found for contextual constructs and nine positive and significant correlations found for self constructs. A summary of predictor correlations are presented in Table 1.5.

Table 1.5

\begin{tabular}{|c|c|c|c|}
\hline \multicolumn{4}{|c|}{ Correlations Between Predictors and Engagement in Studies Under Review } \\
\hline (+/ns correlations) & & dy's Samp & \\
\hline & $\begin{array}{l}\text { African- } \\
\text { American }\end{array}$ & Latino/a & Heterogeneous \\
\hline \multicolumn{4}{|l|}{ Context } \\
\hline positive & 3 & 3 & 8 \\
\hline ns & 2 & 0 & 2 \\
\hline
\end{tabular}

Self

$\begin{array}{clll}\text { positive } & 9 & 0 & 8 \\ \text { ns } & 0 & 0 & 1\end{array}$

Critique of Research on Engagement in Ethnic Minority Youth

Past research on engagement has looked mainly at academic engagement for middle class European American students (Fredricks et al., 2004), and considers its effects on achievement and its predictors - both with contextual and self related factors. While engagement, which looks at how students are involved with their school and the learning process, is a universal concept, it is hard to generalize our understanding of the antecedents and consequences of engagement without a better understanding of how this multidimensional construct applies to a students across other ethnic groups. 
Chapter 1: Introduction 30

Thirteen studies examined engagement in ethnic minority youth, with only a few consistent findings identified in this review. The most consistent finding was that engagement seems to be positively and significantly correlated with achievement. Additionally, it seems engagement could be predicted by both contextual factors, especially teacher and school support, and by self-system processes. However, most of the findings pertained to African American student engagement in the school and classroom. Very little information was provided on Latino/a, Asian American, and Native American students.

Furthermore, even with the findings among these studies, there are still limitations to what conclusive evidence was brought to our overall understanding of engagement for ethnic minority youth. It is the limitations to this body of research as a whole that make it impossible to draw firm aggregate conclusions.

\section{Paucity of Research}

The central problem with research on engagement in students from ethnic minority backgrounds is its scarcity. Although dozens of studies have examined engagement in European American students (Fredricks et al., 2004), only 13 studies could be located that focused on engagement in ethnic minority youth. Out of the 13 studies reviewed, only two examined mean level differences in engagement across ethnic groups and both provided inconclusive results on engagement for ethnic minority students. While some of the research has looked at students from ethnic minority backgrounds, whether in homogeneous or heterogeneous research samples, the results do not show conclusive evidence of whether student engagement predicts achievement 
Chapter 1: Introduction 31

differently for these groups, or what the key predictors of engagement may be. This case in point directly speaks to the dearth of research in this area of study.

\section{Measurement of Engagement}

Even in the few studies that did examine engagement in students of different ethnic backgrounds, there is also a lack of clarity of what constitutes engagement and how it is measured as evidenced by the numbers and types of engagement measures/items used. Of the 13 studies reviewed, there were 16 measures/items used to capture engagement. Although some studies used measures that are well known for their connection to engagement (e.g., Rochester Assessment Package for Schools; Wellborn \& Connell, 1987) other measures used were less readily connected to engagement (e.g., the Intellectual Achievement Responsibility Scale; Crandall, Katkovsky, \& Crandall, 1965). Moreover, for some studies, selecting or combining items from subscales of larger measures used as a part of bigger studies created measures of “engagement”. Hence, there is no convergence on operational definitions of engagement.

This heterogeneity of measures causes many problems in furthering our understanding of the phenomenon of engagement. In addition, the assortment of measures used makes it difficult to compare findings across ethnic groups and between studies. When there are a variety of ways to discuss and capture school engagement, it makes collective conclusions harder to draw. This is primarily due to the fact that the comparisons that could be drawn across studies are limited because of the lack of shared language, conceptualizations, and understanding of what is and what is not engagement. Predictors of Engagement 
Chapter 1: Introduction 32

Another limitation of the current research on engagement in ethnic minority youth was the widely varying range of what is examined and even conceptualized as a predictor of engagement. A total of 29 predictors of engagement were looked at within the 13 studies reviewed. Although most of them could be classified under the umbrellaconstructs of self, context, and academic performance, there was still a lack of agreement about the selection of predictors. Even though many predictors seemed to overlap in definition, there was still a lack of mutually agreed upon definitions of what constitutes a relevant and useful predictor of engagement.

Just as there are drawbacks to not having a clear understanding of what engagement means, there are similar shortcomings when the understanding of what constitutes a predictor of engagement is unclear. First, the ability to compare findings on the relationship between both engagement and its predictors becomes limited when the predictors examined in different studies widely vary. Secondly, combining findings to come to an aggregate conclusion on how these predictors influence engagement becomes restricted because the predictors used by an individual study do not cleanly come under clearly defined constructs of what influences engagement. Thirdly, since conversations about predictors of engagement vary so broadly, it makes it difficult to outline a comprehensive and holistic picture of the pathways to influence engagement.

Finally, the consideration of how ethnic minority status and socioeconomic status (SES) may confound one another must be taken into consideration. Findings from studies that examine engagement differences across ethnic groups while not controlling for SES fail to discern between differences resulting from students' ethnic minority status 
Chapter 1: Introduction 33

versus variations due to students' SES. This is yet another area where concrete conclusions about possible ethnic differences in engagement are difficult to draw.

\section{Theoretical Framework}

Although many of the concerns with research on engagement and its predictors centered on the variety of ways in which they were conceptualized and measured, the larger issue focuses on the lack of a clear theoretical framework that could be used to guide the selection of constructs and measures used in the research of engagement on ethnic minority students. Although all the studies reviewed were looking at student engagement in schools or classrooms, it became clear that very few of the studies had a theoretical model of engagement that guided the questions asked. Without a clear theoretical framework to guide the conceptualization of a construct such as engagement, the result is often heterogeneity of definitions looking at both target constructs and the proximal processes that should influence them. This interferes with our understanding of how and in what ways engagement could be influencing achievement. Moreover, although most of the studies examined self-perceptions and contextual predictors of engagement, there was a surprising deficiency of clear process descriptions of what features of the context and the self that could be most important in shaping engagement for ethnic minority youth. Hence, an overarching problem in this area is the lack of theoretical framework guiding this research. 
This study proposes to add to the scarce research examining academic engagement in ethnic minority groups other than European American students. A key idea of the current study is that with a more comprehensive understanding of how to support the engagement of students from ethnic minority backgrounds, schools and teachers will be better equipped to address the engagement gap, and in so doing also eliminate the achievement gap. Given the malleability of academic engagement, and its connection to such positive outcomes as learning and achievement, it makes it an important construct to understand across minority ethnic groups.

\section{Theoretical Framework: Self-Determination Theory}

Many of the shortcomings of the current research on engagement in ethnic minority students can be addressed by utilizing a comprehensive theoretical model. A theoretical model helps specify our overall conception of engagement and the proximal processes that should shape it. A birds-eye view of engagement encourages us to accurately zero in on clearly defined sub-constructs which, in turn, helps to guide our choices in what questions are asked to capture relevant constructs of engagement and its predictors. Clarity about what the constructs that make up engagement guide the choice of the measures of engagement to utilize.

The current study was guided by Deci and Ryan’s (1985) self-determination theory (SDT). The self-system model of motivational development (SSMMD; presented in Figure 2.1) offers a practical framework for understanding and organizing multidimensional constructs such as engagement. The SSMMD model attempts to explain the associations between a student's experiences of the contextual environment, 
Chapter 2: The Current Study 35

their self-perceptions, their behaviors (e.g., attendance) and their performance

outcomes (e.g., GPA) that is line with self-determination theory. SDT posits that a

student's level of engagement is the main motivational state that impels students' success

in school and influences their academic achievement. Engagement is defined as an

outward reflection of motivation behavior that is demonstrated in the student's

“enthusiastic participation in academic activities in the classroom.” (Marchand \&

Skinner, 2007; Skinner \& Belmont, 1993).

According to self-determination theory (SDT), as well as the self-systems approach, people seek out opportunities and experiences that fulfill their need for relatedness, competence, and autonomy (Deci \& Ryan, 2000). The need for relatedness refers to a student's need to experience themselves as connected, loved, and valued to important others. The need for competence refers to a student's need to experience oneself as effective and knowledgeable in their environment. Lastly, the need for autonomy refers to the student's need to experience themselves as the source of their own actions (Marchand \& Skinner, 2007). Self-system processes (SSPs) are organized around these three foundational psychological needs. They have also been found to be key predictors of student engagement and disaffection (Furrer \& Skinner, 2003; Patrick, Skinner, \& Connell, 1993; Skinner, Zimmer-Gembeck, \& Connell, 1998; Marchand \& Skinner, 2007). SDT assumes that the extent to which students perceive that the school context meets their psychological needs for relatedness, competence, and autonomy in turn determines the level of students' engagement in school (Wang \& Holocombe, 2010). 
Figure 2.1. Self-Determination Model of Engagement

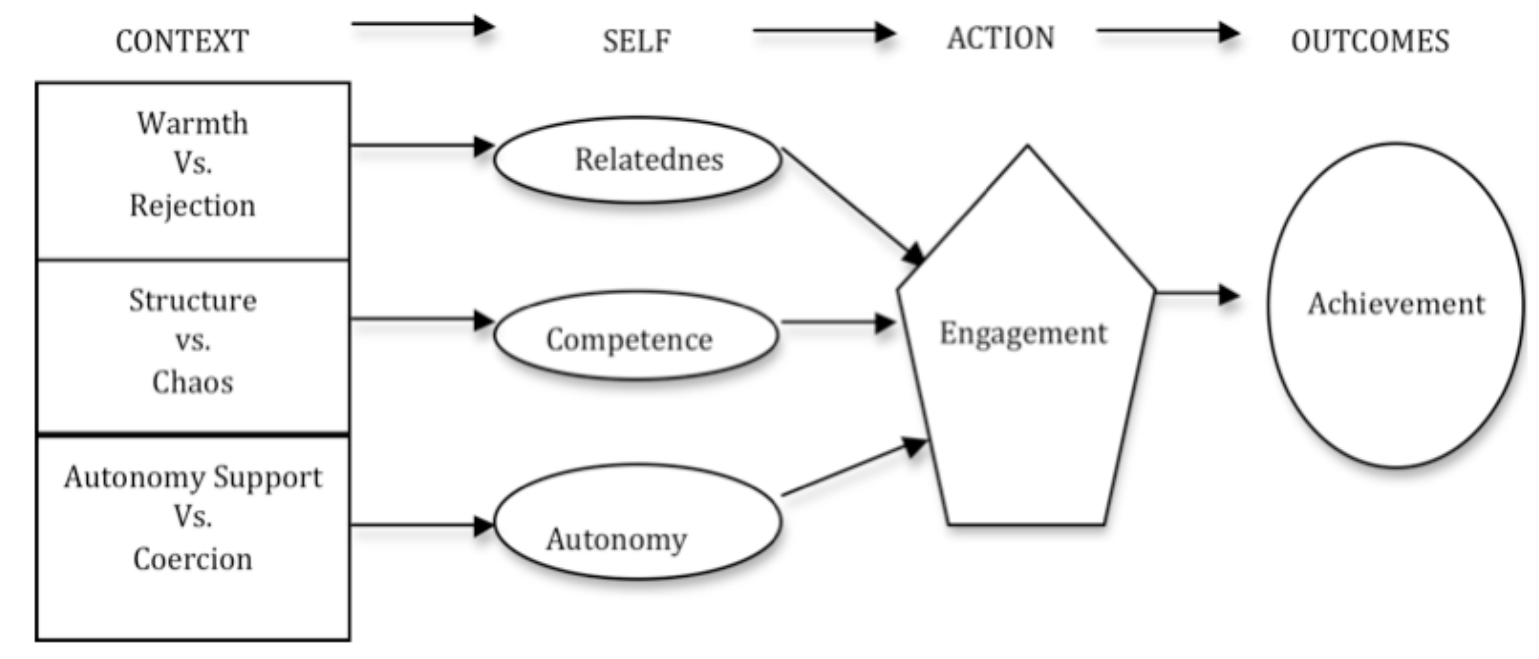

Teacher support. The SSMMD holds that communal partners such as teachers play an important role in providing a context rich in motivational supports. There are three motivational supports that are posited to promote engagement through the meeting of students' needs. Teacher involvement, which refers to the characteristics of the interpersonal relationship (e.g., time and resources dedicated, enjoyment in interactions, etc.) between a student and their teacher, is assumed to fulfill a student's need of relatedness (Skinner et al., 2008). A teacher’s ability to provide structure and explanations that students can grasp cultivates competence in students. Structure refers to the sharing of information in the context that explains how to effectively accomplish desired outcomes (Skinner \& Belmont, 1993). Teachers provide autonomy-support by offering choices, collaborating with students in the decision-making process, and permitting students to pursue their own interests within the school environment. These three teacher support factors make up what are considered the foundational contextual 
constructs of the SSMMD model. They have also been found to play a key role in students' experiences of the school and classroom environments.

By differentiating the context, self, action, and outcomes, this model suggests a clear process view of engagement (action), its consequences (outcomes), and its predictors (context and self). By examining these constructs, a more holistic understanding of student engagement across ethnic groups may be able to be seen. Conceptualization and Measure of Engagement

By using an already well-known measure of student engagement, which clearly draws on the SDT model, the current study ensures the comparability of our study to other studies examining engagement. This model of engagement captures the multifaceted nature of academic engagement, which includes both the behavioral and emotional components as well as their opposites, or behavioral and emotional disaffection. Behavioral engagement includes effortful exertion and persistence, on-task learning behaviors, and classroom participation, whereas emotional engagement encompasses enjoyment, enthusiasm, and interest while participating in class. In contrast, disaffection comprises the absence of persistence and giving up (behavioral) along with feelings of apathy, boredom, or dejection (emotional; Skinner et al., 2009).

This comprehensive view of engagement is important because it allows for a more comprehensive understanding of what influences engagement and the meaningful relationship it has to student achievement. It also enables the multidimensional nature of engagement to be addressed. As the current study seeks to target core components of what engagement is as a multidimensional construct, a published measure of engagement examining these core constructs is utilized. In addition, the employed measure is also the 
Chapter 2: The Current Study 38

most frequently used measure across studies of engagement (Fredricks et al., 2004).

Past research has also established that the measure of engagement is well validated and ensures that its psychometric properties are well established (Connell \& Wellborn, 1991).

This measure has also been compared and validated with in vivo observations of engagement in the classroom (Skinner et al., 2008). By looking at engagement through the lens of a validated measure we are able to make a meaningful contribution to the general understanding of what constitutes engagement.

\section{Contextual and Self as Predictors of Engagement}

If academic engagement can influence students' achievement, it is important to understand how to promote engagement by studying the effects of contextual factors and academic self-systems. In the current study we focus on the self-system processes (SSP) of a sense of belonging, self-efficacy, and autonomy.

\section{Ethnic Minority Students}

This study aims to examine how ethnic group differences may predict student engagement differently or similarly to European American middle class students. We utilize a multi-ethnic sample on which to examine how engagement looks across ethnic groups, while controlling for students' socioeconomic status (SES). In the United States ethnic minority status is confounded with SES. Unless SES is controlled for, it is not possible to examine differences due to ethnicity. The strength of the SDT model is that it is a universal model of motivation that takes into consideration basic human needs that should operate across ethnic groups. This implies that the SDT model can be applied to any given group and that the constructs and their relationships will function in the same way. In our opinion, in the area of engagement, we hypothesize that relatedness and 
Chapter 2: The Current Study 39

involvement are likely to be more important predictors of student engagement although the additional components of competence and autonomy are still hypothesized to exert a substantial influence on engagement. Taking into consideration that all of the constructs of engagement are important, it may be that ethnic minority students who are seen as an "outsider" or "other," in a school environment, may need more support in feeling that they belong and are accepted (e.g., relatedness).

Research Questions

The current study draws on the general SDT conceptual model presented in Figure 2.1 and addresses the following three research questions:

1. Are achievement differences across ethnic groups due to differences in engagement (see Figure 2.2)?

R1a. Does achievement differ across students from different ethnic groups?

R1b. Does engagement differ across students from different ethnic groups?

R1c. Do achievement differences disappear when variations in engagement are

removed? 
Chapter 2: The Current Study 40

Figure 2.2. Model Examining Whether Ethnic Group Differences in Achievement Are

Due to Engagement

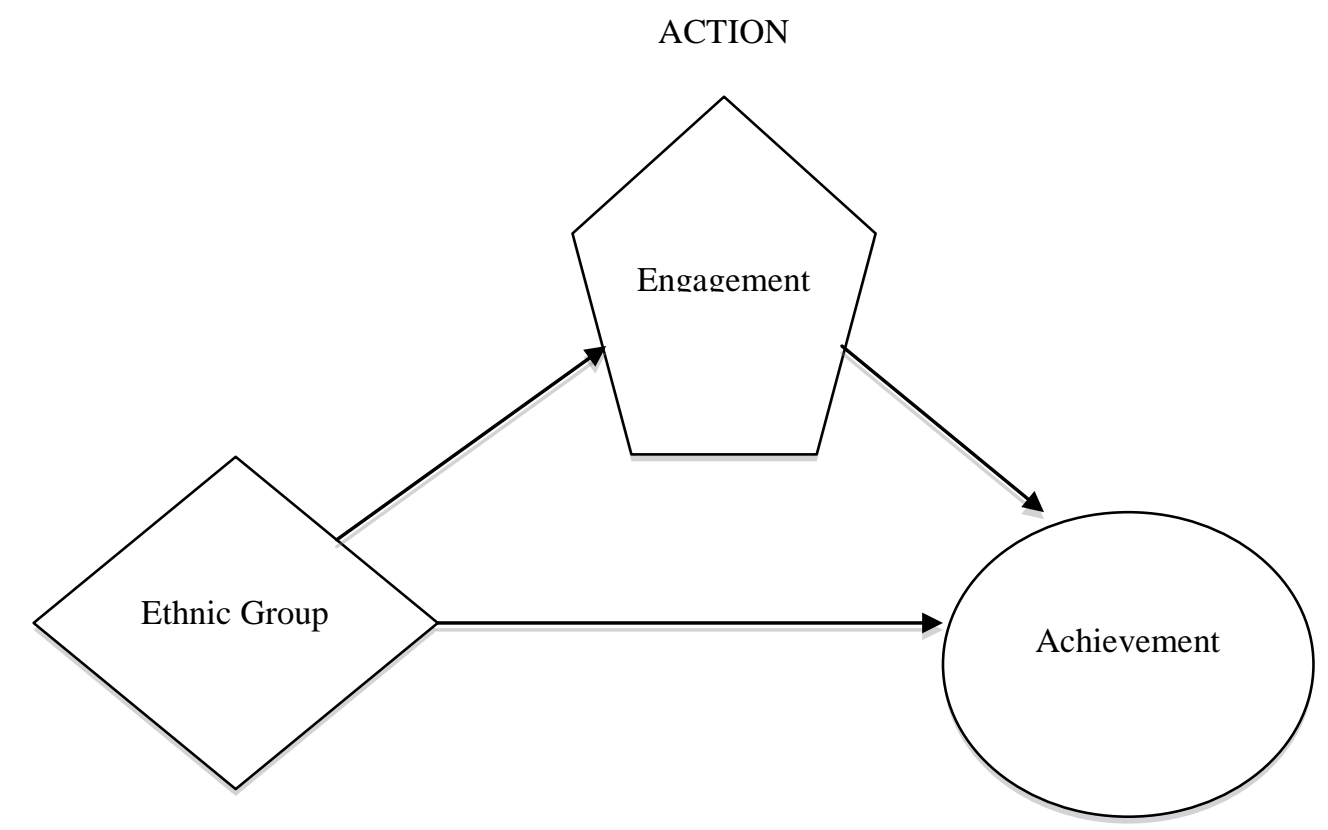

2. Does engagement predict achievement similarly or differently across ethnic groups (see Figure 2.3)?

Figure 2.3. Model Examining Whether Ethnic Group Moderates thee Effects of Engagement on Achievement ACTION $\longrightarrow$ OUTCOMES

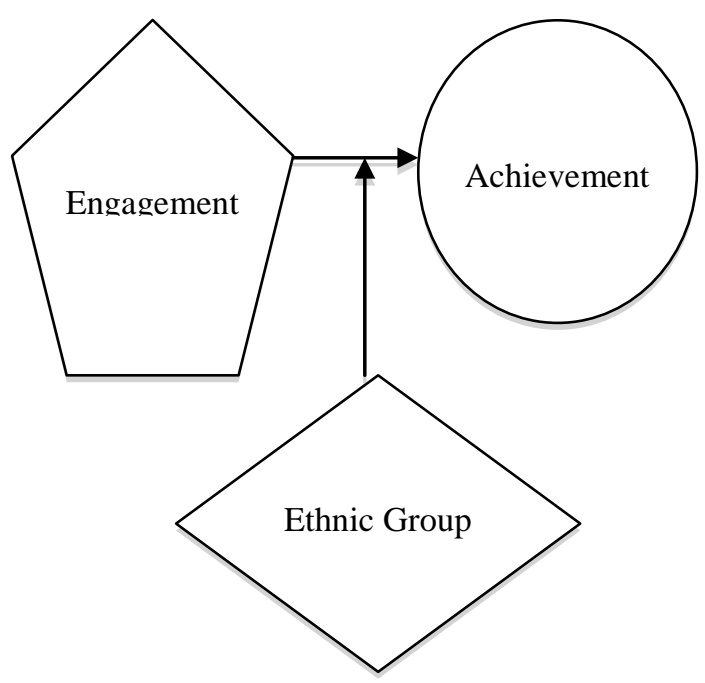


3. Are each of the predictors of engagement the same or different for students from different ethnic groups (see Figure 2.4)?

Figure 2.4. Model Examining Whether the Predictors of Engagement are Moderated by Ethnic Group

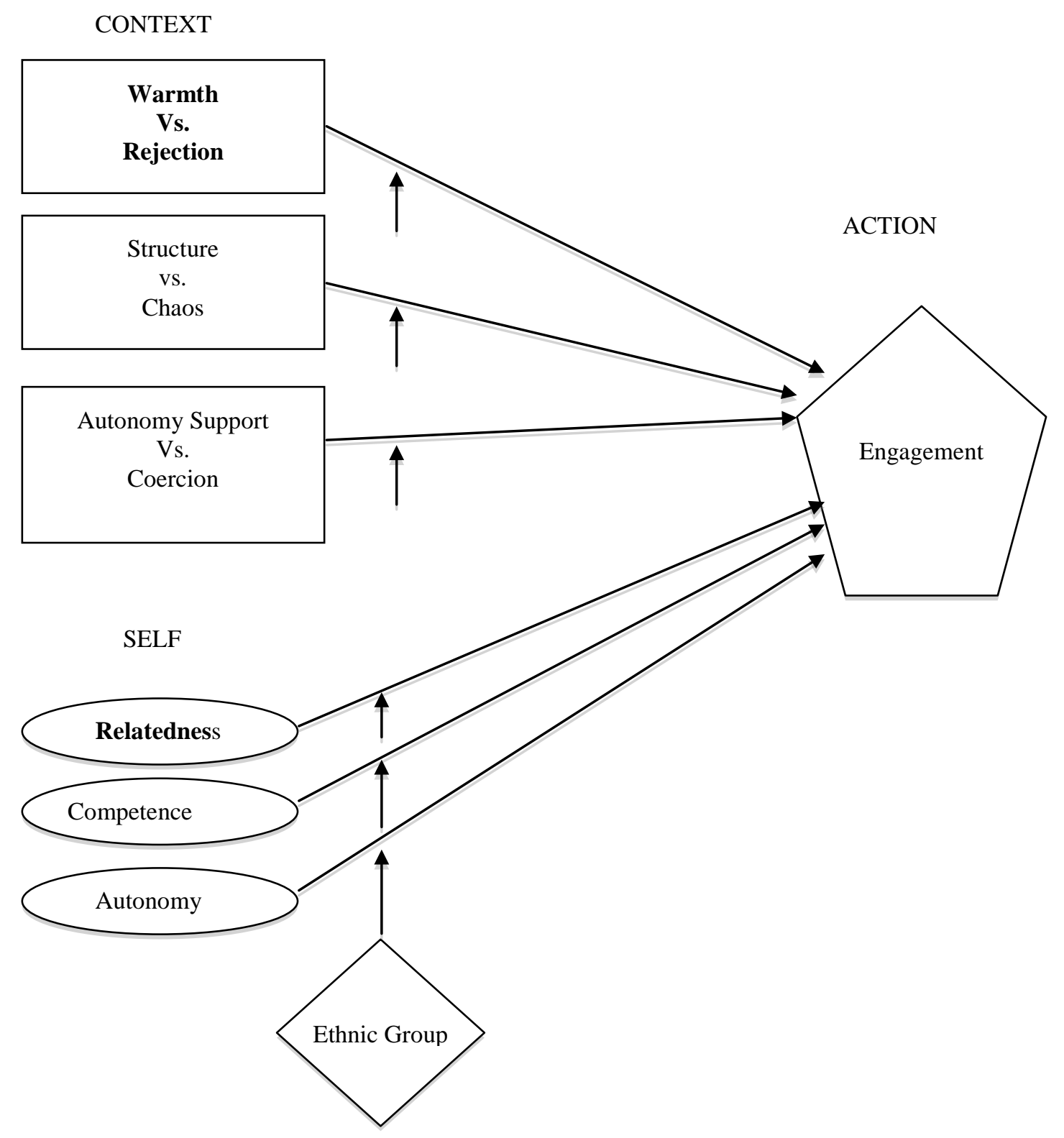


Chapter 3: Research Design \& Method 42 Chapter 3: Research Design and Method

The current study relied on data that came from a larger study whose goal was to evaluate the impact a middle school's garden-based science education program had on students’ engagement and learning. Drs. Ellen Skinner and Thomas Kindermann in the Psychology department at Portland State University (PSU) conducted this larger evaluation project. The Learning Gardens is a garden-based program that incorporates the partnerships of Portland State University (PSU), Portland Public Schools (PPS), and the city of Portland in a collaborative community project that was established in 2005. Originally under the direction of Dilafruz Williams and Pramod Parajuli, and now under the direction of Heather Burns, this project is part of the Leadership for Sustainability Education program at the Graduate School of Education and is supported by a team of faculty, graduate students, and staff. The data for this study were collected in Spring 2008.

Participants

Participants for this study attended a middle school in Portland, OR. At this school, out of the total 33 teachers, there were nine who taught Science as a subject. During the 2007-2008 academic year there were $4896^{\text {th }}, 7^{\text {th }}$, and $8^{\text {th }}$ graders, ranging from age 11 to 15 years old. With 54.6\% ethnic minority students, (24.1\% Hispanic/Latino, 15.3\% Asian/Pacific Islander, 8.4\% African American, 3.5\% multiethnic, and 3.3\% Native American) this school is classified as one of the Portland Public School district's most culturally diverse schools.

Its students tend to come from low socioeconomic families, with $75 \%$ of its student population eligible for free and reduced lunches. Considerable challenges are 
Chapter 3: Research Design \& Method 43

present in lives of these students. Some of these challenges are found in forms of financial struggles (i.e., unemployment), community or family violence, and the impact of drugs and violence. Challenges such as these can be reflected in students’ lowered achievement levels, truancy, increased levels of criminal behavior and/or failure to complete school.

\section{Design and Procedure}

Teachers administered questionnaires to students in a 50-minute class session. At a different time and at their convenience, 6 out of 9 teachers also completed a survey that assessed individual student engagement in their classroom. Data were collected in May 2008 (see Escribano, 2010 for details). Students were asked to report on the following information used for this study: (1) their engagement versus disaffection in school in general; (2) the self-systems processes of relatedness, competence and autonomy; (3) teacher and school support; and (4) demographic information. Respondents used a 5point Likert-type scale to indicate whether each item was (1) totally not true, (2) a little bit true, (3) somewhat true, (4) fairly true, and (5) totally true. Negatively worded items were reverse coded, and items in each scale were averaged to calculate a composite score. Scale scores ranged from 1 to 5, with higher scores indicating more of the respective constructs.

Measures

The current study utilized an instrument comprised of selected items from validated measures (Belmont, Skinner, Wellborn, \& Connell, 1991; Ryan \& Connell, 1989; Wellborn, Connell, \& Skinner, 1990). Three additional scales (Belongingness, Support, and Engagement scales) were included that were developed in a prior study 
Chapter 3: Research Design \& Method 44 (Escribano, 2007), were also included. Each of the latter scales were designed to draw on the constructs of support, belongingness, and engagement for students in the areas of family, school, and peer supports. Psychometric properties for all three scales were satisfactory. Table 3.1 summarizes each of the scales used in the present study, and lists the items that went into them.

Engagement Scale (Skinner, Kindermann, \& Furrer, 2009). This scale taps into the level of involvement, participation, enjoyment, liking, persistence, and investment in the activities of the family, school, and peer domain. It contains 43 items in total. The internal consistencies for the Family (14 items), School (14 items), and Peer (15 items) subscales were .89, .71, and .89 respectively (Escribano, 2007). For the present study nine items were selected for assessing school engagement. Example items are "I look forward to coming to school” and “School makes me angry,” (reverse-coded).

Student Learning and Achievement. Student performance scores such as grades and achievement test scores in Science, Math, and Reading were gathered from student records. An aggregated measure of school performance (cumulative GPA) was computed.

Belongingness Scale (Escribano \& Skinner, in preparation). This scale assesses a youth's sense of belonging, membership, feelings of being valued, feeling important, safe, respected, and cared for /about in the family (14 items), school (14 items), and peer domain (13 items). It contains 41 items in total. The internal consistencies for the Family, School, and Peer subscales were .87, .81, and .86 respectively (Escribano, 2007). For the present study, five items were selected from the school domain. Example items 
Chapter 3: Research Design \& Method 45

are "I feel safe at this school” and "Sometimes I feel like I don't belong to this school," (reverse-coded; as presented in Table 3.1).

Perceived Control and Competence. Student's expectations about the extent to which they can achieve success in school and avoid failure will be assessed using the sixitem Control Belief subscale and the Student Perceptions of Control Questionnaire (Wellborn, Connell, \& Skinner, 1990). This measure taps into students' generalized beliefs about the extent to which they can produce desired outcomes and avoid negative ones in the academic domain. Example items are "If I decide to learn something, I can" and "I can't get good grades, no matter what I do, “ (reverse coded). The internal consistency for this subscale is satisfactory (Cronbach’s alpha = .62; Marchand \& Skinner, 2007; as presented in Table 3.1).

Autonomy Orientation. Five items were selected from Ryan \& Connell’s (1989) measure of academic autonomy, which is composed of 17 items that tap whether students engage in activities because the feel coerced or because they derive satisfaction and enjoyment from the learning task. These items are from two of the four subscales: (1) Intrinsic Self-Regulation (two items), which refers to doing school work because it is inherently enjoyable; and (2) Identified Self-Regulation (four items), which refers to reasons for undertaking a learning task due to a desire for learning and understanding. Example items are "Why do I do my classwork? Because we are learning important things" (identified).

Teacher as a Social Context Questionnaire - Student-Report (Belmont, Skinner, Wellborn, and Connell, 1991). This measure is comprised of 52 items that tap into student experiences of their interactions with their teachers along three dimensions (i.e., 
Chapter 3: Research Design \& Method 46 involvement, structure, and autonomy support). It is comprised of the three subscales from which a total of eight items were selected and adapted for the present study. The first subscale, Teacher Involvement, included three items that assesses students' experiences about their teacher's involvement in the classroom. These items tap into warmth and affection, knowledge about the student's needs, dedication of resources, and dependability versus hostility and neglect. Example items are “My teachers just don’t understand me” and "I can’t really count on my teachers, “(reverse-coded). Only negative items were included in this subscale. The second subscale, Teacher Provision of Structure, included two item measures the kind and amount of structure, including clarity of expectations and contingency, versus chaos experienced by students from their teachers. The items were "I know what my teacher expects of me in class" and "My teacher keeps changing the rules in our class," (reverse-coded). After reverse-coding the negative items, a composite score will be calculated by first aggregating these eight items and the three items for teacher support and then averaging the 11 items (as presented in Table 3.1).

Teacher Support and School Climate Scale (Escribano \& Skinner, in preparation). This scale measures the degree to which the youth perceives his/her teachers/school as communicative, responsive, caring, positive, helpful, dependable, available, attuned, accepting, warm, and encouraging. It contains 15 items in total. The internal consistencies for Teacher Support subscales Teacher Involvement (6 items), Teacher Structure (3 items) and Teacher Autonomy Support (3 items) were .87, .76, .63 and .64 respectively (Escribano, 2007). For the present study, three items were selected from the school domain. Example items are, "My teachers understand me" and "If I have a 
Chapter 3: Research Design \& Method 47

problem, I can go to my teachers.” Three items were developed that assess the psychological school environment experienced by the students. These items tap into student perceptions of their teacher's perceptions of their ability to succeed, fairness, and the relationships with school personnel. Example items are "People here know I can do good work" and "The rules at this school are so unfair," (reverse-coded; as presented in Table 3.1).

Demographic items. Demographic items include five questions that ask students to report their age, race/ethnicity, month of birth, place of birth, and primary language(s) spoken at home. Students were asked to select race/ethnicity options, which included White, Asian, African American, Native Hawaii/Pacific Islander, Hispanic/Latino, and Other. From these options students were asked to mark all that apply to their own racial/ethnic background. 
Table 3.1

Index of Items by Study Constructs

\begin{tabular}{|c|c|}
\hline Constructs & Items \\
\hline \multicolumn{2}{|c|}{ Engagement versus Disaffection } \\
\hline \multirow[t]{9}{*}{ Engagement } & I look forward to coming to school. \\
\hline & I enjoy learning new things in school. \\
\hline & I try hard to do well in school. \\
\hline & When we work on something in class, I feel bored. (-) \\
\hline & When I'm in class, I feel mad. (-) \\
\hline & School makes me angry. (-) \\
\hline & When I'm in class, I just act like I'm working. (-) \\
\hline & In school, I don’t work very hard. (-) \\
\hline & I can't stand doing school work. (-) \\
\hline \multicolumn{2}{|c|}{ Achievement } \\
\hline \multicolumn{2}{|c|}{ Grades and Test Scores } \\
\hline & Science grades and test scores \\
\hline & Math grades and test scores \\
\hline & Reading grades and test scores \\
\hline \multicolumn{2}{|c|}{ Self-System Processes } \\
\hline \multirow[t]{5}{*}{ Relatedness } & I feel safe at this school. \\
\hline & I feel like a real part of Lane. \\
\hline & I feel like the people at this school don't understand me. (-) \\
\hline & I feel like an outsider at this school. (-) \\
\hline & Sometimes I feel as if I don't belong to this school. (-) \\
\hline Competence & $\begin{array}{l}\text { If I decide to learn something hard, I can. } \\
\text { I can do well in school if I want }\end{array}$ \\
\hline
\end{tabular}


I can get good grades in school.

I can't get good grades, no matter what I do. (-)

I can't stop myself from doing poorly in school.

$(-)$

I can't do well in school, even if I want to. (-)

\section{Autonomy}

Intrinsic

Identified

Teacher Involvement

\section{Because it's fun.}

Because it's

interesting.

Because I want to understand the subject.

Because homework helps me learn more.

Because we are learning important things.

Because doing well in school is important to

me.

My teachers understand me.

My teacher really cares about me.

If I have a problem, I can go to my teachers.

People here know I can do good work.

My teachers just don't understand me. (-)

Sometimes I wonder if my teachers really like me. (-)

I can’t really count on my teachers. (-)

I know what my teacher expects of me in class.

My teachers treat me fairly.

The rules at this school are so unfair. (-)

My teachers keep changing the rules in our class. (-) 
Teacher Autonomy Support
My teachers explain why the things I learn in school are important.

People here are always telling me what to do. (-)

My teachers don't give me much choice about how I do my schoolwork. (-)

My teachers never talk about how I can use the things we learn in school. (-) 


\section{Chapter 4: Results}

The central goal of this study was to explore differences across ethnic groups in engagement, and its predictors and outcomes. This was accomplished in three steps. First, students from four ethnic groups were compared for their mean levels of engagement and academic outcomes, and analyses examined whether ethnic differences in achievement would disappear when differences in engagement were removed. The second aim was to examine whether ethnic groups differ in the extent to which engagement predicted achievement. The third aim was to examine whether predictors of engagement (both contextual factors and self-perceptions) differed across ethnic groups. A detailed description follows of the analyses that were conducted and their results.

\section{Missing Data}

For the purposes of this study $6^{\text {th }}$ and $7^{\text {th }}$ graders with GPA data were selected. Study participants were also selected if they identified with only a single pan-ethnic group (African American, Asian/Pacific Islander, Hispanic/Latino/a, or European American). These decisions resulted in a dataset that included 194 cases with complete data, and excluded 55 sixth and seventh graders who self-identified as Native American ( $n=3)$, multi-ethnic $(n=44)$, or were missing ethnic identity data $(n=8)$.

\section{Descriptive Analyses}

Measurement properties and descriptive statistics. All analyses were conducted using SPSS 16.0. Items from each scale were individually aggregated and then averaged to form a composite score, in which higher scores reflect higher levels of each respective construct (e.g., school climate). Subscales that tap into a particular construct contained both positively and negatively worded items. Negative items were reverse-coded and 
combined with positive items. Initial descriptive analyses were conducted to calculate the means, standard deviations, and internal consistencies (Cronbach's alpha) for all the variables used in the study. They are presented in Table 4.1. Internal consistency reliabilities using Cronbach’s alpha for most subscales were satisfactory $(\leq .77)$. The internal consistencies for competence ( $\alpha=.62$ ), teacher autonomy support ( $\alpha=.64$ ), teacher structure ( $\alpha=.63)$, and for school climate $(\alpha=.61)$, were adequate.

The low internal consistencies for teacher autonomy support, teacher structure, and school climate may have been due to the small number of items (three items) comprising each scale. It is important to note that the correlations and regressions utilizing these four variables may be attenuated due to their low internal consistencies.

An examination of the means demonstrated that the distributions of all scales were each slightly negatively skewed. Mean scores tended toward the upper half of the score range. On examining the skewness statistics, only one scale slightly exceeded the acceptable level of 1.0 (for competence -1.02). The kurtosis analyses demonstrated that all variables fell below 2.5; therefore, no transformations were conducted (Kline, 2005). These observations suggest that the students viewed themselves as receiving structure and support from teachers and other school staff in a positive school climate, as competent and autonomous students (more identified than intrinsic) who felt that they belonged to their school and were engaged in the learning process. The standard deviations for all scales were moderate, ranging from .72 to 1.31 , which suggests that the variability in scale scores between students is adequate to detect significant effects. 
Chapter 4: Results 53

Table 4.1

Summary of Means, Standard Deviations, and Internal Consistencies for each Construct

\begin{tabular}{|c|c|c|c|c|}
\hline Scale & $\begin{array}{l}\text { Number } \\
\text { Of Items }\end{array}$ & $\alpha$ & $M$ & $S D$ \\
\hline Overall School Supports & 15 & .87 & 3.57 & .82 \\
\hline School Climate & 3 & .61 & 3.64 & .94 \\
\hline Teacher Support & 12 & .87 & 3.55 & .87 \\
\hline Teacher Involvement & 6 & .76 & 3.39 & .95 \\
\hline Teacher Structure & 3 & .63 & 3.81 & .99 \\
\hline $\begin{array}{l}\text { Teacher Autonomy } \\
\text { Support }\end{array}$ & 3 & .64 & 3.60 & 1.03 \\
\hline Self System Processes & 17 & .84 & 3.69 & .70 \\
\hline Relatedness & 5 & .78 & 3.59 & .99 \\
\hline Competence & 6 & .62 & 4.24 & .72 \\
\hline Autonomy & C & 00 & ? 2 & 100 \\
\hline Intrinsic & 2 & 85 & 243 & 129 \\
\hline Identified & 4 & .88 & 3.61 & 1.14 \\
\hline Engagement & 9 & .85 & 3.84 & .79 \\
\hline
\end{tabular}

Note. $N=194$. Range of all scores are from 1-5. Higher scores indicate more of the respective construct. 
Intra-constructs correlations. Correlations among constructs were calculated as an indication of the degree of interdependence that may exist among components of each construct. The bivariate relations among the constructs that comprised engagement, overall school support, and the aggregate SSPs were in the expected direction: the majority of correlations were small to moderate ( $r$ ranged from .30 to .64). In terms of the SSPs (see Table 4.2), the correlations among relatedness, competence, and autonomy were moderate (average $r=.34$ ). For overall school support (see Table 4.3), student experiences of a supportive school environment correlated positively with student experiences of teacher involvement, teacher structure, and teacher autonomy (average $r=$ .58). These high correlations (which approach the level of the internal consistencies) suggest that the scales may be measuring similar underlying dimensions and can be aggregated to calculate a total score. These correlations justified the decision to create a variable, labeled overall school support, which combined school climate and the three dimensions of teacher support. The internal consistency of the 15-item aggregated variable was .87, which likewise provided evidence that the items tapping each component were closely related to each other.

Inter-construct correlations. The correlations between engagement and the variables assessing school climate, teacher support, SSPs, and GPA are presented in Table 4.4. Consistent with the motivational model, all correlations were positive and significant. In terms of the connection between school/teacher supports and engagement, the correlations were relatively high (average $r=.64$ ). In terms of the SSPs, the correlations of engagement with relatedness and autonomy and were relatively high 
Chapter 4: Results 55

(average $r=.63)$, except competence $(r=.38)$ whose comparatively low correlation with engagement may be due to its relatively lower internal consistency reliability. In terms of GPA, the correlation between GPA and engagement was moderate $(r=.39)$.

Tables 4.4 also shows the inter-construct corrections among school supports, SSPs, and GPA. In terms of GPA, its correlations with SSPs and school supports were moderate to high ( $r$ ranged .30 to .77). In terms of the connections between context and self-perceptions, correlations were also moderate to high ( $r$ ranged .31 to .70 ). 
Table 4.2

Intra-Construct Correlations among the Self-System Processes

\begin{tabular}{llccc}
\hline & & \multicolumn{3}{c}{ Self-System Processes } \\
\cline { 3 - 5 } & & Relatedness & Competence & Autonomy \\
\hline \multirow{2}{*}{ SSPs } & Relatedness & -- & - & -- \\
& Competence & .40 & -- & -- \\
& Autonomy & .36 & .26 & -- \\
\hline
\end{tabular}

Note. $N=194$. All correlations are significant at a 0.05 level. $p<.05$.

Table 4.3

Intra-Construct Correlations among Indicators of School and Teacher Support

\begin{tabular}{|c|c|c|c|c|c|}
\hline & & $\begin{array}{l}\text { School } \\
\text { Climate }\end{array}$ & $\begin{array}{c}\text { Teacher } \\
\text { Involvement }\end{array}$ & $\begin{array}{l}\text { Teacher } \\
\text { Structure }\end{array}$ & $\begin{array}{c}\text { Teacher } \\
\text { Autonomy } \\
\text { Support }\end{array}$ \\
\hline \multirow[t]{4}{*}{$\begin{array}{l}\text { Overall School } \\
\text { Support }\end{array}$} & School Climate & -- & -- & -- & -- \\
\hline & Teacher Involvement & .53 & -- & -- & -- \\
\hline & Teacher Structure & .48 & .71 & -- & -- \\
\hline & $\begin{array}{r}\text { Teacher Autonomy } \\
\text { Support }\end{array}$ & .52 & .66 & .59 & -- \\
\hline
\end{tabular}

Note. $N=194$. All correlations are significant at the 0.01 level. 
Table 4.4

Inter-Construct Correlations Between Engagement, School Supports, Self-System Processes, and GPA

\begin{tabular}{|c|c|c|c|c|c|}
\hline Study Variables & Engagement & GPA & Relatedness & Competence & Autonomy \\
\hline Overall School Supports & $.77 * *$ & $.43^{* * *}$ & $.70 * *$ & $.47 * *$ & $.60 * *$ \\
\hline School Climate & $.64^{* *}$ & $.34 * *$ & $.65 * *$ & $.33^{* *}$ & $.43 * *$ \\
\hline Teacher Involvement & $.69 * *$ & $.34 * *$ & $.62 * *$ & $.39 * *$ & $.54 * *$ \\
\hline Teacher Structure & $.61^{* *}$ & $.33 * *$ & $.50 * *$ & $.45^{* *}$ & $.53 * *$ \\
\hline Teacher Autonomy Support & $.61^{* *}$ & $.30 * *$ & $.57 * *$ & $.31 * *$ & $.51 * *$ \\
\hline Relatedness & $.60 * *$ & $.31 * *$ & -- & -- & -- \\
\hline Competence & $.38 * *$ & $.30 * *$ & -- & -- & -- \\
\hline Autonomy Orientation & $.65 * *$ & $.30 * *$ & -- & -- & -- \\
\hline Cumulative GPA & $.39 *$ & -- & -- & -- & -- \\
\hline $\begin{aligned} \text { Note. } & N=194 . \\
& * p<.05 \\
& * * p<.01 \\
& * * * p=.001\end{aligned}$ & & & & & \\
\hline
\end{tabular}


Chapter 4: Results 58

Research Question 1. Are achievement differences across ethnic groups due to differences in engagement?

Research Question 1a. Does achievement differ across students from different ethnic groups?

To assess ethnic differences in achievement, students’ GPAs were examined for mean level differences across groups. A one-way ANOVA indicated significant differences in achievement levels across ethnic groups $F(3,190)=14.16, p<.001$. Follow-up pairwise comparisons using Tukey’s HSD revealed that Asian/Pacific Islander students $(M=3.53)$ had significantly higher GPAs with the mean levels higher than the European American students (mean differences, $m d=.77$ ), the African American students ( $m d=1.24)$, and the Hispanic/Latino/a students $(m d=.84)$, who did not differ from each other. Table 4.5 summarizes the means and standard deviations in GPA by ethnic groups.

Research Question 1b. Does engagement differ across students from different ethnic groups?

To assess ethnic differences in engagement students’ overall engagement levels were examined for mean level differences across groups. A one-way ANOVA indicated that there were no significant differences in engagement levels across ethnic groups $F(3$, $190)=2.17$, ns. Table 4.6 summarizes the means and standard deviations in student engagement by ethnic group. Figures 4.1 and 4.2 depict mean levels in engagement and achievement by ethnic group. 
Table 4.5

Mean Levels of Achievement for Students from Four Ethnic Groups

\begin{tabular}{|c|c|c|c|c|c|c|c|c|}
\hline \multirow[b]{3}{*}{ Achievement } & \multicolumn{2}{|c|}{$\begin{array}{l}\text { African } \\
\text { American } \\
(n=11)\end{array}$} & \multicolumn{2}{|c|}{$\begin{array}{l}\text { Hispanic/ } \\
\text { Latino/a } \\
(n=47) \\
\end{array}$} & \multicolumn{2}{|c|}{$\begin{array}{c}\text { Asian/Pacific } \\
\text { Islander } \\
(n=52)\end{array}$} & \multicolumn{2}{|c|}{$\begin{array}{c}\text { European } \\
\text { American } \\
(n=84) \\
\end{array}$} \\
\hline & $M$ & $S D$ & $M$ & $S D$ & $M$ & $S D$ & $M$ & $S D$ \\
\hline & 2.29 & .88 & 2.69 & .87 & 3.53 & .60 & 2.76 & .83 \\
\hline
\end{tabular}

Note. $N=194$.

Table 4.6

Mean Levels of Engagement for Students from Four Ethnic Groups

\begin{tabular}{|c|c|c|c|c|c|c|c|c|}
\hline & \multicolumn{2}{|c|}{$\begin{array}{l}\text { African } \\
\text { American } \\
(n=11)\end{array}$} & \multicolumn{2}{|c|}{$\begin{array}{l}\text { Hispanic/ } \\
\text { Latino/a } \\
(n=47) \\
\end{array}$} & \multicolumn{2}{|c|}{$\begin{array}{c}\text { Asian/Pacific } \\
\text { Islander } \\
(n=52)\end{array}$} & \multicolumn{2}{|c|}{$\begin{array}{c}\text { European } \\
\text { American } \\
(n=84)\end{array}$} \\
\hline & $M$ & $S D$ & $M$ & $S D$ & $M$ & $S D$ & $M$ & $S D$ \\
\hline Engagement & 3.69 & 1.15 & 3.79 & .82 & 4.08 & .55 & 3.73 & .82 \\
\hline
\end{tabular}

Note. $N=194$. 
Figure 4.1: Mean Levels of Student Achievement Across Ethnic Groups

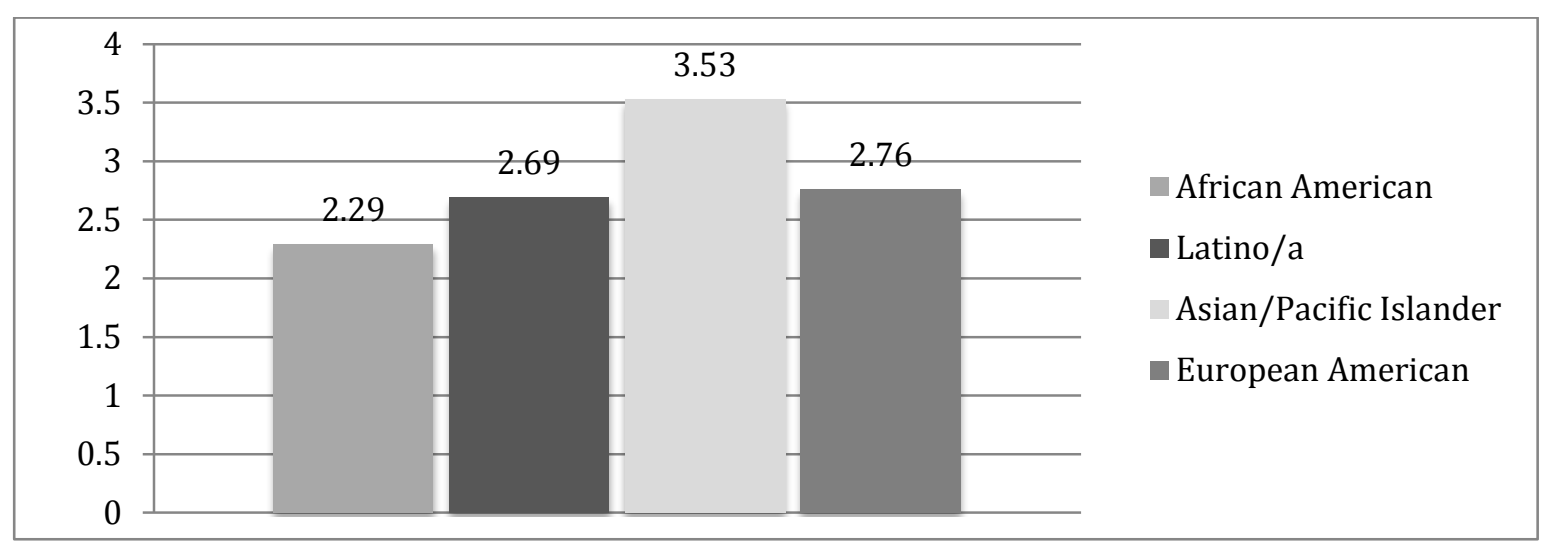

Note. $N=194$ 
Figure 4.2: Mean Levels of Student Engagement Across Ethnic Groups

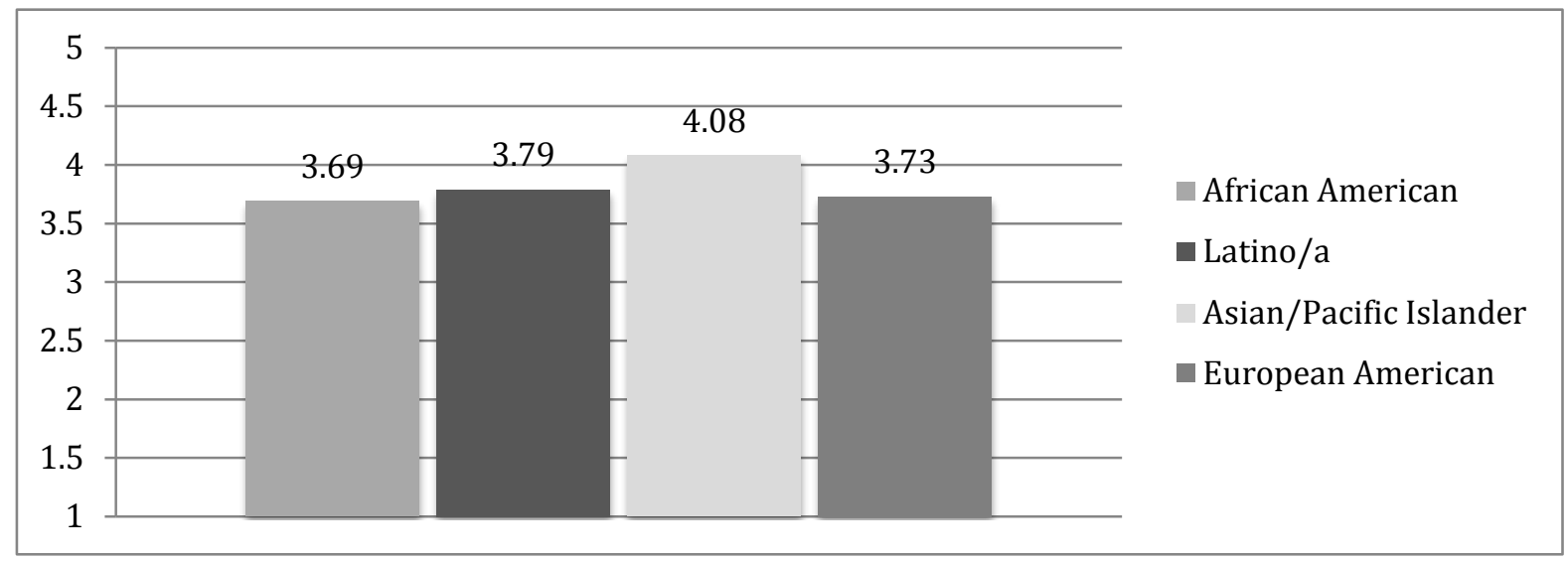

Note. $N=194$ 
disappear when variations in engagement are removed?

A two-step process was used to assess whether or not differences in academic achievement across ethnic groups would disappear once variations in engagement are controlled for. First, a test of the homogeneity-of-slopes assumption was conducted, and then it was planned to follow up with an analysis of covariance (ANCOVA), with ethnicity as the independent variable, achievement as the dependent variable, and engagement as the covariate. The expectation was that the main effect of ethnicity on achievement would no longer be significant, once variation in levels of engagement were controlled. At the first step, however, it was found that the test of the homogeneity-ofslopes indicated that the interaction between student ethnicity and engagement was significant. This significant interaction suggests that the slopes differ or that the differences on the dependent variable (achievement) among groups vary as a function of the covariate engagement. The decision was then made not to conduct and ANCOVA but instead to examine simple main effects for ethnicity at each level of engagement (low, medium, and high).

To divide students into three levels of engagement, the following steps were taken: (1) students were rank ordered on their scores of engagement (2) students were divided into thirds (approximately increments of 65), and (3) for scores that were on both sides of the cut-off the researchers moved them all to one particular group or another. This resulted in students in one of the three levels of engagement low (range of engagement scores $=-2.11$ to $0.33, n=60$ ), medium (range $=0.44$ to $1.00, n=69$ ), or 
high (range $=1.11$ to $1.67, n=65$ ), with representation of each of the four ethnic groups at each level.

Table 4.7 summarizes ANOVA results for student achievement by engagement level across ethnic groups and significance levels. The ANOVAs revealed that, for students with medium and high levels of engagement there were no significant differences in achievement. However, for students with low levels of engagement significant variances in achievement as a function of ethnicity were found. Follow-up pairwise comparisons showed that Asian/Pacific Islander students had higher mean levels of achievement $(M=3.10)$ compared to African American $(M=1.92)$, Hispanic/Latino $(M=2.26)$, and European American $(M=2.56)$ students, who did not differ from each other. Figure 4.3 summarizes mean levels of achievement across ethnic groups at each level of engagement. Table 4.8 summarizes mean level differences in engagement after controlling for ethnicity. 
Table 4.7

Mean Levels of Achievement as a Function of Ethnicity for Students from Three Levels of Engagement

\begin{tabular}{|c|c|c|c|c|c|}
\hline & African & Hispanic/ & Asian/ & European & \multirow{4}{*}{$\mathrm{F}(3,56)=2.92, \mathrm{p}<042^{*}$} \\
\hline & American & Latino/a & Pacific Islander & American & \\
\hline Low & 2.22 & 2.47 & 2.98 & 2.49 & \\
\hline Engagement & $(n=2)$ & $(n=2)$ & $(n=0)$ & $(n=9)$ & \\
\hline Medium & 2.43 & 2.74 & 3.93 & 2.77 & \multirow{2}{*}{$F(3,65)=.12, n s$} \\
\hline Engagement & $(n=3)$ & $(\mathrm{n}=18)$ & $(n=12)$ & $(n=27)$ & \\
\hline High & 2.65 & 3.02 & 3.81 & 3.06 & \multirow{2}{*}{$F(3,61)=.40, n s$} \\
\hline Engagement & $(n=6)$ & $(n=30)$ & $(n=35)$ & $(n=48)$ & \\
\hline
\end{tabular}

Note. $N=194$.

$$
* p<.05
$$


Table 4.8

Achievement Means for Each Ethnic Group After Controlling for Engagement

\begin{tabular}{|c|c|c|c|c|}
\hline & $\begin{array}{c}\text { African } \\
\text { American } \\
(n=11)\end{array}$ & $\begin{array}{c}\text { Hispanic/ } \\
\text { Latino/a } \\
(n=47)\end{array}$ & $\begin{array}{c}\text { Asian/Pacific } \\
\text { Islander } \\
(n=52)\end{array}$ & $\begin{array}{c}\text { European } \\
\text { American } \\
(n=84)\end{array}$ \\
\hline & $M$ & $M$ & $M$ & $M$ \\
\hline Achievement & 2.45 & 2.74 & 3.39 & 2.77 \\
\hline
\end{tabular}


Figure 4.3: Achievement Mean Levels by Engagement Levels Across Four Ethnic Groups

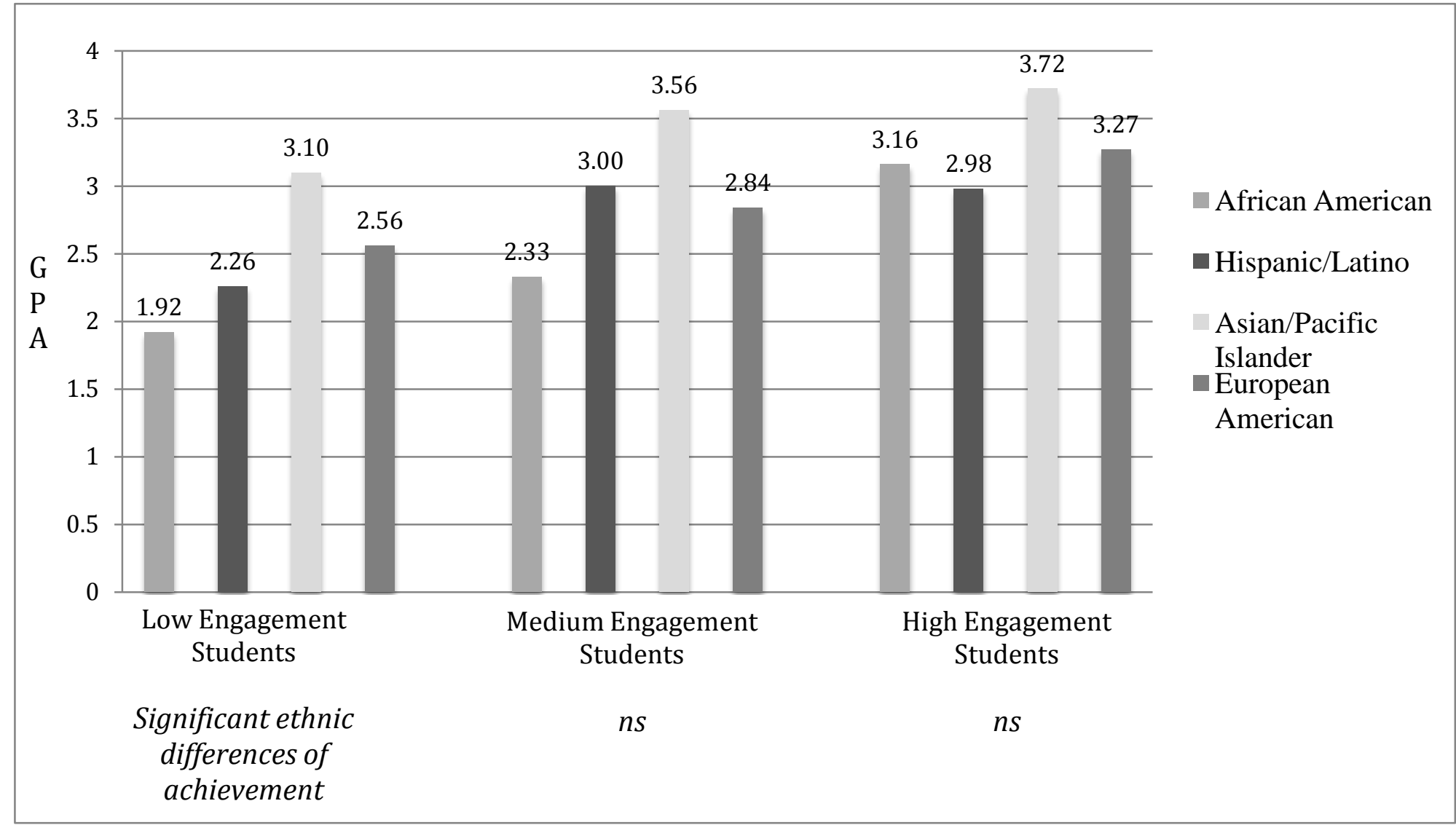

Note. $N=194$. 
Research Question 2. Does engagement predict achievement similarly or differently across ethnic groups?

To assess whether engagement predicts achievement similarly or differently across ethnic groups, multiple linear regression analyses were employed. The overall model used achievement as the dependent variable, and engagement, ethnicity, and the interaction term between engagement and ethnicity (calculated as their cross product) as the independent variables. Of interest was the interaction term; a significant interaction would indicate that there were ethnic differences in the connection between engagement and achievement. Regression analyses revealed that the overall model, significantly predicted achievement $F(3,190)=13.49, p<.001 . R^{2}$ for the model was .18 , and adjusted $R^{2}$ was .16 .

Table 4.9 displays the unstandardized regression coefficients $(B)$, intercept, and standardized regression coefficients $(\beta)$ for each variable. Two of the independent variables were not significant unique predictors of achievement: engagement $(t=1.14$, $n s)$ and ethnicity $(t=-1.85, n s)$. However, the interaction between engagement and ethnicity predicted achievement significantly and uniquely $(t=2.09, \mathrm{p}<.05)$ (see Table 4.10). Together, along with the interaction, the variables contributed $17.6 \%$ in shared variability with the dependent variable. However, it was the interaction between the two variables engagement and ethnicity that seemed to drive the model's overall significance. 
Table 4.9

Multiple Linear Regression Predicting Student Achievement

\begin{tabular}{lccc}
\hline & $B$ & $\beta$ & Sig. \\
Engagement & .16 & .15 & $p<.27$ \\
Ethnicity & .40 & .59 & $p<.07$ \\
Engagement * Ethnicity & .12 & .72 & $\boldsymbol{p}<.04$ \\
\hline
\end{tabular}

Note. $N=194$

Follow-ups on this significant interaction were conducted by creating a dummy variable for each ethnic group, which contrasted students who belonged to the target group (e.g., were Hispanic) and those who did not (e.g., were not Hispanic). Then regressions were run using achievement as the dependent variable, and engagement, target ethnic group and their interaction as the independent variables. A significant interaction would indicate the connection between engagement and achievement was different for the target ethnic group than for the rest of the sample.

Follow-up regression analyses revealed that only the interaction term contrasting European American and non-European American students was significant $F(3,190)=$ 15.13, $p<001$. $R^{2}$ for the model was .19 , and adjusted $R^{2}$ was .18 whereas the interaction terms were not significant for all other ethnic groups. Table 4.10 displays the unstandardized regression coefficients $(B)$, standardized regression coefficients $(\beta)$, and significance level for the overall model. Each of the independent variables was a significant predictor of achievement: engagement $(t=6.03, p<.001)$, ethnicity $(t=-2.25$, $p<.05)$, and the interaction term between engagement and ethnicity $(t=-2.63, p<.05)$ each significantly predicted achievement for European American versus non-European 
Chapter 4: Results 69

American students. Together, along with the interaction, the variables contributed $19 \%$ in shared variability with the dependent variable.

Table 4.11 displays the unstandardized regression coefficients $(B)$ and standardized regression coefficients $(\beta)$ for the other pan-ethnic groups. Table 4.12 displays correlations between engagement and achievement for each pan-ethnic group. As can be seen, engagement was correlated for each group (range $=.31-.75)$. According to the multiple regressions, the correlation between engagement and achievement for the European American students was significantly lower than that of the non-European American students 
Table 4.10

Multiple Linear Regression Predicting Student Achievement for European American versus Non-European American Students

$\begin{array}{lccc} & B & \beta & \text { Sig. } \\ \text { Engagement } & .59 & .54 & p<.001 \\ \text { Ethnicity } & 1.25 & .72 & p<.03 \\ \text { Engagement * Ethnicity } & -.38 & -.84 & \boldsymbol{p}<.009 \\ \text { Note. } N=194 & & & \end{array}$


Table 4.11

Interaction Terms for Engagement and Ethnicity as Unique Predictors for Student Achievement for Each Ethnic Group

B Sig.

Engagement *

(African American vs.

0.17

0.18

ns

non-African American)

Engagement *

(Hispanic/Latino vs. non-

0.13

0.26

ns

Hispanic/Latino)

Engagement *

(Asian/Pacific Islander vs. non-Asian/Pacific Islander)

Note. $N=194$. 
Table 4.12

Correlations Between Engagement and Achievement by Ethnic Group

African American

$$
(n=11)
$$

Hispanic/ Latino/a

$$
(n=47)
$$

Asian/ Pacific Islander

$$
(n=52)
$$

European American

$$
(n=84)
$$

Note. $N=194$.

$$
\begin{aligned}
& * \mathrm{p}<.05 \\
& * * \mathrm{p}<.01 \\
& * * * \mathrm{p}<.001
\end{aligned}
$$

Note. $N=194$.
$.75^{* *}$

$.49 * * *$

$.31 *$

$.31 *$ 

for students from different ethnic groups?

To assess whether the connection between engagement and its potential predictors differed across ethnic groups multiple linear regressions were employed. The potential predictors were: relatedness, competence, autonomy, teacher structure, teacher involvement, teacher autonomy support, overall teacher support, and overall school support. For each potential predictor of engagement, a regression was conducted with engagement as the dependent variable, and three independent variables: the predictor, ethnicity, and the interaction between the potential predictor and ethnicity. For the selfsystem processes, none of the interaction terms were significant predictors of engagement. Table 4.13 displays the unstandardized regression coefficients (B), intercept, and standardized regression coefficients $(\beta)$ for each set of multiple regressions.

For overall school support, regression analyses revealed that the overall model was significant in predicting engagement $F(3,190)=136.96, p<.001 . R^{2}$ for the model was .60, and adjusted $R^{2}$ was .60. However, the interaction term between overall school supports and ethnicity $(t=1.43, n s)$ was not significant in predicting engagement. Together, along with the interaction, the variables contributed $45.4 \%$ in shared variability with the dependent variable. Table 4.16 for predictor engagement variable correlations across ethnic groups.

For overall teacher support, all three independent variables were significant: overall teacher support $(t=4.10, p<.001)$, ethnicity $(t=-4.84, p<.001)$, and the interactions between teacher support and ethnicity $(t=5.49, p<.001)$. See Table 4.14. 
Together, along with the interaction, the variables contributed $45.4 \%$ in shared variability with the dependent variable.

Follow-ups on this significant interaction were conducted by creating a dummy variable for each ethnic group, which contrasted students who belonged to the target group (e.g., were Hispanic) and those who did not (e.g., were not Hispanic). Then regressions were run using engagement as the dependent variable, and the predictor, target ethnic group and their interaction as the independent variables. A significant interaction would indicate the connection between the predictor and engagement was different for the target ethnic group than for the rest of the sample. Table 4.15 displays the interaction terms for overall teacher support across the four ethnic group comparisons.

None of the interaction terms for the separate components of teacher support were significant. For teacher involvement, regression analyses revealed that the overall model was significant in predicting engagement $F(3,190)=61.61, p<.001 . R^{2}$ for the model was .49, and adjusted $R^{2}$ was .49. However, the interaction term between teacher involvement and ethnicity was not significant $(t=-.58, n s)$. For teacher structure, regression analyses revealed that the overall model was significant in predicting engagement $F(3,190)=40.31, p<.001 . R^{2}$ for the model was .39 , and adjusted $R^{2}$ was .38. However, the interaction term between teacher structure and ethnicity was not significant $(t=-.21, n s)$. For teacher autonomy support, regression analyses revealed that the overall model was significant in predicting engagement $F(3,190)=54.40, p<.001$. $R^{2}$ for the model was .46 , and adjusted $R^{2}$ was .45 . The interaction term between teacher autonomy support and ethnicity $(t=-.76, n s)$ was not found to be significant. 
Table 4.13

Interaction Terms Between SSPs and Ethnicity from Multiple Linear Regression Predicting Student Engagement

\begin{tabular}{lccc}
\hline & $B$ & $\beta$ & Sig. \\
Relatedness * Ethnicity & .05 & .37 & $n s$ \\
Competence * Ethnicity & .08 & .59 & $n s$ \\
Autonomy * Ethnicity & & -.15 & $n s$ \\
\hline Note. $N=194$. & -.02 &
\end{tabular}

Table 4.14

Multiple Linear Regression Predicting Teacher Support on Student Engagement

\begin{tabular}{|c|c|c|c|}
\hline & $B$ & $\beta$ & Sig. \\
\hline $\begin{array}{l}\text { Teacher } \\
\text { Support }\end{array}$ & .24 & .31 & $p<.001$ \\
\hline Ethnicity & -.48 & -.78 & $p<.001$ \\
\hline Teacher Support * Ethnicity & .15 & .94 & $p<.001$ \\
\hline Note. $N=194$. & & & \\
\hline
\end{tabular}


Table 4.15

Interaction Terms Between Overall Teacher Support by Ethnic Group from Multiple Linear Regression Predicting Student Engagement

$B \quad \beta \quad$ Sig.

Overall Teacher Support

(African American vs. non-African American)

21

$n S$

Overall Teacher Support *

(Hispanic/Latino vs. non-Hispanic/Latino)

.04

.07

$n S$

Overall Teacher Support

(Asian/Pacific Islander vs. non-Asian/Pacific Islander)

$-.18$

$-.37$

ns

Overall Teacher Support *

(European American vs. non-European American)

$-.01$

$-.02$

$n s$

Note. $N=194$ 
Table 4.16

Correlations Between Engagement and Self-System and Contextual Predictors for Each Ethnic Group

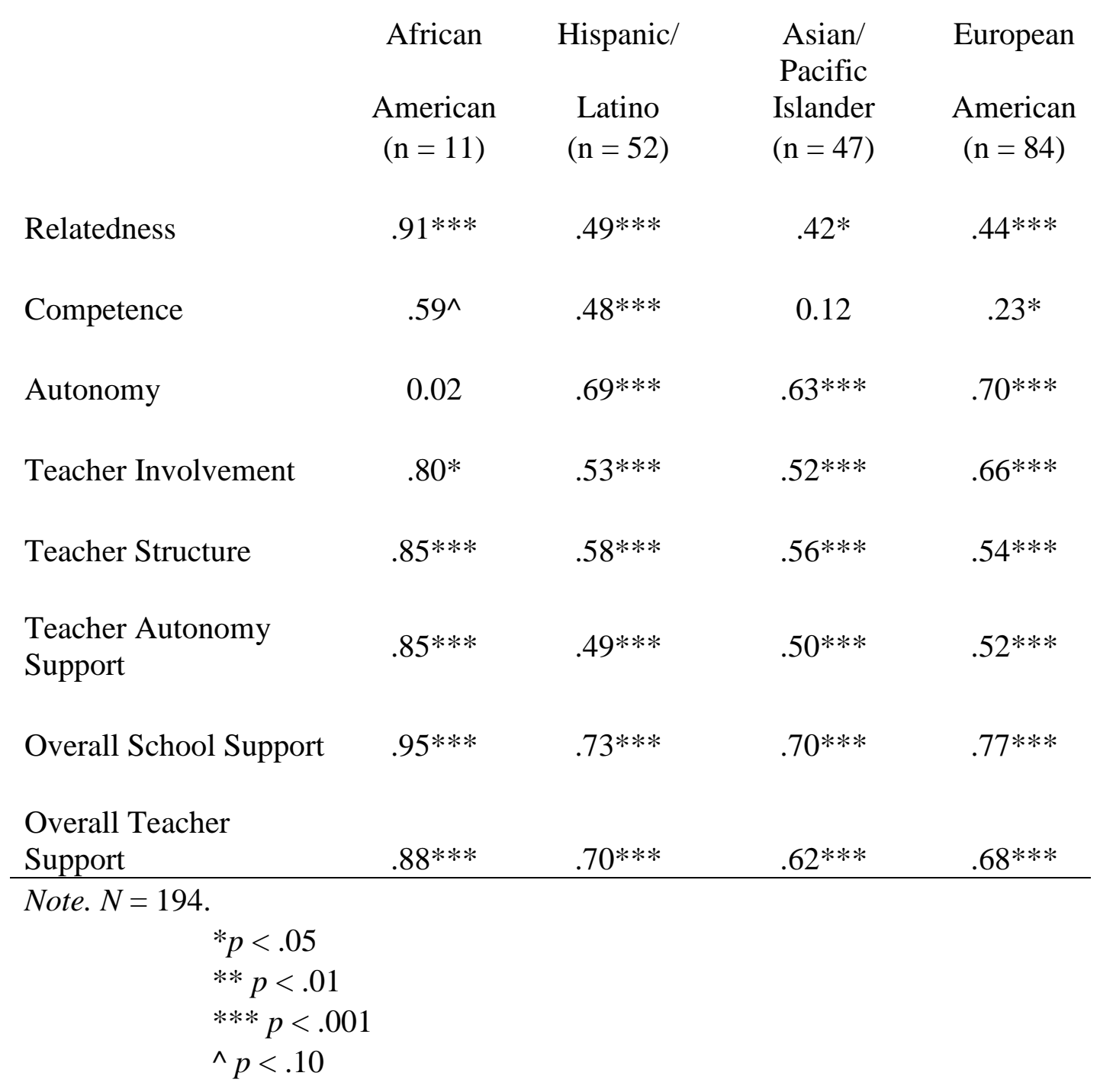


A study was conducted to examine ethnic differences in engagement as a contributor to ethnic differences in achievement. The study utilized and ethnically heterogeneous sample of $6^{\text {th }}$ and $7^{\text {th }}$ graders in order to examine three issues: (1) ethnic differences in mean levels of achievement and engagement, and whether ethnic differences in achievement would disappear once levels of engagement were controlled; (2) ethnic differences in engagement as a predictor of achievement; and (3) ethnic differences in the self-system and contextual predictors of engagement. This discussion chapter summarizes the findings of the current study, then details its strengths and limitations, discusses the most important findings in the context of the larger literature on engagement and achievement in ethnic minority students, suggests how future studies may expand upon the present work, and highlights a few important applications of the study's findings to improving the academic experiences of students from all ethnic groups.

\section{Summary of Findings}

Following a summary of the descriptives, the findings of the current study are summarized according to the three main research questions. In general, the descriptive findings were consistent with the overall expectations of the larger theoretical model guiding the study. Measures used to tap key study constructs exhibited internal consistency reliabilities that were adequate to satisfactory, with intra-construct correlations demonstrating significant relationships among proposed components, and the inter-construct correlations revealing significant relationships among study constructs, all in the expected directions. 
Chapter 5: Discussion 79

Research question one was broken down into three sub-questions. For research question 1a, analyses designed to examine whether achievement differs for students across ethnic groups, found that significant mean level differences in achievement only for Asian American students, whose level of achievement was higher than all the other ethnic groups. For research question $1 \mathrm{~b}$, in analyses designed to examine if engagement differs for students across ethnic groups, no mean level differences in engagement were found. For research question 1c, in analyses designed to examine if controlling for variations in engagement would cause achievement differences between ethnic groups to disappear, a test of the simple main effects demonstrated that ethnic differences in achievement were found only at the low level of engagement. At that level, the same pattern of achievement differences were found as for the sample overall: the only significant effect was for Asian/Pacific Islander students, whose achievement was higher than all other ethnic groups, who did not differ from each other. However, at medium and high levels of engagement, there were no significant differences in achievement across the four ethnic groups.

For research question 2, in analyses designed to examine whether engagement predicts achievement differently across ethnic groups, a multiple linear regression revealed that the interaction between engagement and ethnicity was significant as a predictor of achievement. Follow-up regression analyses comparing target ethnic groups to all others revealed that only one comparison, European American students, compared to non-European American students, showed a significant interaction between engagement and ethnicity in predicting achievement. An examination of the correlations between engagement and achievement for each ethnic groups revealed that, although 
Chapter 5: Discussion 80

engagement is an important predictor of achievement for all students regardless of ethnicity, it is even more important for non-European American (compared to EuropeanAmerican) students.

Finally, for research question 3, in analyses designed to examine whether potential predictors (SSPs and contextual constructs) correlate with student engagement similarly or differently across ethnic groups, a multiple linear regression was conducted on each SSP (relatedness, competence, and autonomy) and each contextual construct (teacher involvement, teacher structure, teacher autonomy support, and overall teacher support). For the SSPs, none of the interaction terms between the target SSP and ethnicity significantly predicted engagement, indicating that all three SSPs are important to engagement for all students regardless of ethnicity. For the contextual constructs, only overall teacher support had a significant interaction with ethnicity. However, follow-up multiple linear regressions revealed that no ethnic group comparisons had a significant interaction with overall teacher support. This indicated that overall teacher support is significant in predicting engagement, for students from all four ethnic groups.

\section{Strength and Limitations}

As with any study, this study contains both strengths and limitations. Specifically, these issues will be discussed in regards to the conceptualization, sample, measurement, design, data analytic strategy, and generalizability of the study.

Conceptualization. A significant strength of this study is the careful conceptualization of student engagement rooted in Deci and Ryan's self-determination theory. This theory's thorough conceptualization of the individual needs and conduits of motivation cleanly encompass the underlying mechanisms and processes at work in 
Chapter 5: Discussion 81

student's academic engagement and consequently their achievement. This is the same

guiding theory that was used the most in the studies reviewed covered in this current study’s literature review.

Sample. An important limitation of the current study was the relatively small size of the sample and the correspondingly low statistical power. This could have made it difficult to detect interactions with ethnicity. A larger sample size would have provided enough power to allow for the detection of interactions with ethnicity, or at the very least, to be certain that lack of differences were not due to the lack of power to actually detect them.

An especially clear limitation of this study was the small number of African American students represented in the sample $(n=11)$. With a sub-group this small, in comparison to other groups represented in this study, it is difficult to draw strong conclusions about how engagement predicts achievement for this particular ethnic group and also how they compare to the other ethnic groups represented from the analyses that were run. This also poses an interesting counterpoint when reflecting on the amount of studies on engagement conducted with more representative samples of African American students, especially those with homogeneous samples, as the current study illustrates in its review of the literature. The issue of representation is important because it speaks directly to this study's ability to contribute to the research findings of engagement and its predictors as a relevant for African American students.

One concrete limitation based on this study’s sample stemmed from decisions about who would be selected to be included or excluded. One such decision was to exclude students who self-identified as multi-ethnic. This decision was made because the 
Chapter 5: Discussion 82 research questions were focused on understanding ethnic difference in the predictors and outcomes of student engagement. However, by excluding multi-ethnic students from these analyses it also limits our ability to generalize these results to this population. Additionally, decisions to combine different Latino and Asian/Pacific Islander groups (e.g., from different countries of origin) disregard the innate heterogeneity of these panethnic groups. Therefore, the current study’s findings are not clearly generalizable to each possible subgroup.

Measurement. In addition to a concrete theoretical model, a significant strength of this study is the measure of student engagement used, the Rochester Assessment Package for Schools

(RAPS). This measure of engagement, along with being a well-validated, published measure, also has established psychometric properties containing the core ideas of what clear conceptualization constitutes engagement.

Additionally, a limitation of the current study was the measure of competence. This initially presented as a problem when looking at the internal consistency reliability for this construct ( $\alpha=.62$ ) even though six survey items made up this construct. Given the low level of internal consistency reliability, when compared to the other study constructs, the current study's competence construct showed a low relationship between other study variables. An alternative interpretation for these findings is that the survey items in our current measure of competence, are not accurately targeting the construct of competence.

Future studies would be recommended to look at our understanding of competence and how it is measured. This could begin with classroom observations to study 
Chapter 5: Discussion 83

competence in action and then revisiting the questions to see which, if any, could be reworded to provide a more comprehensive measurement of student competence. With these new/revised questions, additional studies could be conducted to see if the internal consistency of this construct has increased. If so, then correlational analyses could be conducted to examine the relationships between the new competence measure and other features of the SSMMD look.

Lastly, the issue of using only student-report information is another limitation of this study. The implications of this are that with only the student's perspective we are limited in our interpretation of the results. To truly further our understanding of how engagement, and its predictors, influence student achievement levels across ethnic groups, we need to have observational measures along with teacher-report surveys. With this information, we again garner a better understanding of predictors and contextual factors that influence engagement, along with more information on how engagement impacts student achievement. In the same vein, the use of student-reports to capture ethnic identity may further limit the interpretation of this study's findings. It may be that the use of information about ethnic identity classifications from parents or school records would yield a better basis on which to run these same analyses.

Design. The design of the study was a one time cross-sectional study. This made it impossible to examine whether engagement predicts changes in achievement across time, or whether any of the "predictors” of engagement actually predict changes in engagement across the school year. All of the analyses were only able to examine associations between concurrent measures. Hence, it is possible that achievement is also a predictor of engagement, and that a student's level of engagement predicts the support the 
Chapter 5: Discussion 84

teacher will provide (Skinner \& Belmont, 1993). Future studies with a longitudinal

design including multiple time points are needed to more thoroughly examine the issue of direction of effects.

Analytic strategy. Another limitation of the current study is that full pairwise comparisons of homogeneous subgroup to homogeneous subgroup were not conducted. Being able to drill down deeper, past homogeneous sub-groups compared to all others in the sample, would provide a better understanding of how engagement contributes to students’ academic achievements similarly or differently across ethnic groups (e.g., Hispanic/Latino students compared to Asian/Pacific Islander students). Inferences from a study of this magnitude may help inform decisions around interventions applied to diverse populations of students while still considering the importance of a particular student's ethnic membership orientation.

Generalizability. A particular strength of this study is its generalizability to other student populations. Given that most of the students who participated in this study came from families living at or below poverty level this gave us the ability to hold socioeconomic status (SES) constant. Even though the socioeconomic status of the participating students was homogenous, the ethnic minority representation was quite diverse. This offers the ability for meaningful comparisons between ethnic groups to be made. At the same time, however, replication would be needed to see if these same findings held true for families of different socioeconomic status.

An important consideration when thinking of the generalizability of the current study is the fact that the school itself was a unique and high functioning school that provided an intervention of sorts with its Learning Gardens. The distinctive qualities of 
Chapter 5: Discussion 85

this school could be why the typical achievement gap patterns were not observed there. This implies that these finding might not generalize to more typical schools around the nation.

\section{Implications and Future Studies}

The present study seeks to contribute to the understanding of the ethnic differences in engagement and achievement. While engagement proved to be a significant predictor of engagement for all students (non-European American more than European American) there are also further implications in understanding how engagement and its predictors influence overall student achievement. Better understanding of the phenomena could be critical to interventions employed to eliminate the current ethnic achievement gap. This study explores the idea that increasing student engagement at school and in the classroom would be a feasible and reasonable target for intervention. Applications of these findings to interventions could have a lasting impact on student learning and achievement.

Engagement and the achievement gap. The current study did not find the typical pattern of ethnic gaps in student achievement. The standard pattern usually finds that both Asian/Pacific Islander and European American students significantly outperform their Hispanic/Latino and African American counterparts. While the current study did find one portion of the typical pattern in its high performing Asian/Pacific Islander students, the additional parts of this pattern were not found among these groups of students. One possible explanation for the a-typical pattern found in this study could be that this school is already investing heavily in the engagement and achievement levels of its students.

Additionally, no ethnic differences in engagement were found. Hence, the ethnic 
Chapter 5: Discussion 86

differences in engagement in this study did not mirror the standard national

achievement gap., nor did they mirror the ethnic gaps in achievement levels found in this study. Nevertheless, one important finding of the current study is that at medium and high levels of engagement ethnic differences in achievement level disappear. The implications of this finding is that if attention is given to the students with low levels of engagement to raise their engagement level to medium or high, ethnic differences may no longer be significant. This suggests that by raising students’ engagement levels high enough, variability in achievement washes out because everyone is achieving well.

In the current study, when looking at the implications of engagement level on achievement, it is also important to explain why Asian/Pacific Islander students were able to achieve at significantly higher levels than all the other represented ethnic groups, even at low levels of engagement. One possibility is that they were still more engaged than students from the other ethnic groups. A second possibility is that for Asian/Pacific Islander students, it was their emotional engagement that was low, while their behavioral engagement was at a level that still allowed them to outperform the other ethnic groups. Other research on the dynamics between behavioral and emotional engagement suggest that behavioral engagement is the primary driver of academic performance (Skinner et al, 2008).

Ethnicity, social class, and immigration status. As the current study demonstrated, engagement is an important predictor of student academic success for all students regardless of ethnic identity, which speaks to the universality of the SSMMD model. With that, it is important to note that engagement was found to be even more salient predictor of achievement for non-European American students than for their European 
Chapter 5: Discussion 87

American counterparts. The implications of this finding are that consideration for engagement for all students should be accounted for with considerable attention being given to students who do not identify as European American.

A recommendation for future studies would be to find a heterogeneous sample of students, that had representative samples across the sub-groupings (including a larger sample of African-American students), and to conduct mean level comparisons of engagement and achievement in a similar manner conducted presented in the current study. Another future study possibility could also be to examine engagement and achievement differences across ethnic groups for students with medium and high SES statuses. This sort of study replication would be needed to see if these same finding trends held true for families from different socioeconomic statuses besides just low SES. These findings would increase the generalizability of this type of work to other student populations.

While the current study aimed to examine ethnic differences in student engagement it did not look at the impact of a student's immigrant status. Immigrant status, understood as being either U.S. or non-U.S. born, is likely to have a significant impact on a student's acuity of their school context as well as their perceptions of their self-system processes in the school/classroom environment. The fact that this demographic marker was not taken into consideration for this current study means that when looking at an ethnic group (e.g., European American) differences in which students were U.S. versus non-U.S. born were not taken into consideration. Despite the fact that a large portion of the European-American students in this study spoke Russian as a first language, the issue of English language attainment was not taken into consideration 
Chapter 5: Discussion 88

within the parameters of this current study. Language attainment could prove to have a

salient impact on how a student's perceptions around self-system processes (e.g., relatedness) and contextual factors (e.g., teacher involvement) are perceived by the student.

A recommendation for future studies could be to examine the relationship between a student's immigrant status and their level of academic engagement and how that linkage influences the academic achievements of these students. Given the increasing level of diversity of our education system, especially in the areas of ethnic and immigrant representations in student populations, these future studies may share some valuable insights into these very real self-identification factors for how students identify and the ways in which they impact a student's learning experience.

Relatedness. An examination of how the self-system processes were related to engagement for students from ethnic groups revealed that relatedness was the only SSP that showed high and significant association with engagement across all student groups. This suggests that improving students' feelings of relatedness and belonging might be an especially effective way of fostering engagement. The current study did not examine whether students from ethnic minority groups have lower levels of relatedness compared to their European-American counterparts. Future studies could examine the possibility of mean level differences in relatedness across ethnic groups. Furthermore, future studies could look at the school institution itself to ask who it was built for and what is it that students bring with them to make them feel a part of the school's fabric.

Autonomy. Students' autonomy orientation is a considerable predictor on the SSMMD model especially considering the direct implied influence a teacher can have via 
Chapter 5: Discussion 89

teacher autonomy support (an SSMMD contextual construct). Intrinsic autonomy

orientation is an individual's inherent interest and enjoyment in an activity. Identified autonomy orientation is an individual's conscious valuing of an activity. In the current study, autonomy was collapsed into one construct, overall autonomy, as a larger marker of student's autonomy levels. However, a better understanding on how these two autonomy orientations influence students' engagement experiences would be valuable while allowing a better picture of the varied and shared impact of SSPs to be painted to an even more drilled down level.

Future studies should consider this delineation in a student's possible autonomy orientations to better understand which type of autonomy orientation impacts student engagement the most. Further examination of these implications could lead to an even more fine tuned understanding of how these internal-motivating factors play a role in the actions (engagement) and outcomes (achievement) of students. In turn, findings around what contextual factors influence each of the respective autonomy orientations would further flesh out our understanding of how to positively impact a student's autonomy orientation and therefore a student's engagement level.

School climate. A better understanding of the school environment as a conduit for student engagement may be achieved by exploring how individual contextual factors significantly influence engagement, while taking into account more holistic contextual constructs that include the teacher and school climate. A recommendation for future studies is to examine which possible combinations of teacher-driven and school-driven contextual supports are most likely to promote student engagement and achievement levels. Such studies may help further our understanding of how teachers and the school 
environment work together to influence students.

\section{Applications to Educational Practice}

A guiding motivation of this project is that the findings from this study will help to inform school administrators and teachers in their effort to make data-driven decisions that benefit the motivation, achievement, and overall school experience of students from ethnic minority and low socioeconomic backgrounds. A few of the key findings that may have important applications are: (1) although mean level differences in engagement and achievement may not mirror each other, engagement has a strong positive relationship with achievement across ethnic groups; (2) engagement is more important for predicting academic achievement for non-European American students; and (3) teacher supports (teacher involvement, structure, and autonomy support) are significant in predicting engagement as a collective (i.e., overall teacher supports), as well as individually. The following section includes some suggestions for how these findings may be applied in schools.

Engagement as a significant predictor of achievement across ethnic groups. Taking into consideration that student engagement is relevant for all students' success should help teachers and school administrators to recognize the importance of enhancing and building upon student's engagement levels. Given the universal importance of engagement, this encourages schools to seriously consider employing school-wide initiatives that promote student engagement. Additionally, as teachers work towards improving student achievement, efforts put towards interventions that speak to student engagement levels should be worth the investment.

Recommendations from this research study would be to focus on directing 
Chapter 5: Discussion 91

interventions towards increasing student engagement, and levels specifically towards students with low engagement levels. These interventions would be designed not to label students as having "low engagement," but rather to help boost their current level of engagement to bring them to the same level as the medium or highly engaged students. Additionally, it is the recommendation of the current study that these interventions focus on the students' feelings of relatedness and on their experiences with their teachers as facilitators of engagement for the students whose engagement levels are low.

Engagement as a better predictor of achievement for non-European American students. If educators are aware that ethnic differences in the extent to which engagement predicts achievement show that it is especially important for non-European American students, then teachers and administrators might expect that non-European American students may benefit more from interventions designed to enhance or ameliorate a student's engagement level. This could prove to be especially important when taking into consideration how a school may address their own ethnic level achievement gaps.

The findings from the current study imply that, just as in past research engagement has shown to be a significant predictor of student achievement, it my be even more important non-European American students. With this information educators may be equipped to speak to this trend by offering interventions that especially bolster engagement for non-European American students. Depending on which ethnic group may be in question these interventions may vary depending on which predictor(s) are relatively more salient for the ethnic group in question. The present study suggests that a sense of relatedness and teacher motivational support should benefit engagement across 
many ethnic groups.

Holistic view of contextual constructs. Future applications should take into consideration that students may be more influenced by the combination of teachers' overall contextual supports rather than by one individual component alone. This could lead to teachers and school administrators taking responsibility for providing a wellrounded classroom environment to promote student success. It would take a conscious effort to provide contextual supports in all three areas of teacher support (involvement, structure, and autonomy support) in a dynamic environment that sustains students. Given the flow of the SSMMD model, these contextual supports should also directly influence the development of students' SSPs.

Implications at this level would mean that instead of a school or a teacher paying attention to training in just one component of contextual support, professional development and reflection opportunities would encourage teachers to look at the impact of multiple contextual supports and their interplay upon one another. The consideration of how these teacher-based predictors interact is important given that the teacher is the foundational impetus for the way in which each kind of predictor is put into practice. Deliberation by administrators and teachers alike on these issues may lead them to find ways of effectively promoting all of these contextual predictors at the same time. If they can accomplish this important task, they may see both the engagement and achievement of students from all ethnic groups flourish. 
References 93

\section{References}

Alliance For Excellent Education. (2010). High school dropout rates in America. Retrieved from: http://www.all4ed.org/publication_material/understanding_HSgradrates.

Betts, J., Appleton, J., Reschly, A., Christenson, S., \& Huebner, E. (2010). A study of factorial invariance of the student engagement instrument (SEI): Results from middle and high school students. School Psychology Quarterly, 25, 84-93.

Booker, K. (2006). School belonging and the African American adolescent: What do we know and where should we go? The High School Journal, April/May, 1-7.

Connell, J. \& Wellborn, J. (1991). Competence, autonomy, and relatedness: A motivational analysis of self-system processes. In Gunnar, M. \& Sroufe, L. (Eds.), Self processes and development (pp. 43-77). Hillsdale, NJ, England: Lawrence Erlbaum Associates, Inc; England.

Connell, J., Spencer, M. \& Aber, L. (1994). Educational risk and resilience in AfricanAmerican youth: Context, self, action, and outcomes in school. Child Development, 65, 493-506.

Connell, J., Halpem-Felsher, B., Clifford, E., Warren, C., \& Usinger, P. (1995). Hanging in there: Behavioral, Psychological, and contextual factors affecting whether African American adolescents stay in high school. Journal of Adolescent Research, 10, 41-63.

Daly, B., Shin, R., Thakral, C., Selders, M., \& Vera, E. (2008). School engagement among urban adolescents of color: Does perception of social support and neighborhood safety really matter? Youth Adolescence, 38, 63-74. 
Deci, E.l., \& Ryan, R.M. (1985). Intrinsic motivation and self-determination in human behavior. New York: Plenum.

Dotterer, A., McHale, S., \& Crouter, A. (2009). Sociocultural factors and school engagement among African American youth: The roles of racial discrimination, racial socialization, and ethnic identity. Applied Developmental Science, 13, 61-73.

Elmore, G., \& Huebner, E. (2010). Adolescents’ satisfaction with school experiences: Relationships with demographics, attachment relationships, and school engagement behavior. Psychology in the Schools, 47, 525-537.

Escribano, L. M. (2007). Why are adolescents attracted to and motivated to join gangs? An examination of proximal processes underlying gang membership in Latino youth. Unpublished master’s thesis, Portland State University, Portland.

Escribano, L. M. (2010). Exploring school engagement as a protective factor for youth at risk of joining gangs. Unpublished doctoral dissertation. Portland State University, Portland.

Fredricks, J.A., Blumenfeld, P.C., \& Paris, A.H. (2004). School engagement: Potential of the concept, state of the evidence. Review of Educational Research, 74, 59-109.

Fuller, B. \& Coll, C. (2010). Learning from Latinos: Contexts, families, and child development in motion. Developmental Psychology, 46, 559-565.

Garcia-Reid, P., Reid, R., \& Peterson, N. (2005). School engagement among Latino/a youth in an urban middle school context: Valuing the role of social support. Education and Urban Society, 37, 257-275.

Gonzalez, R. (2009). Beyond affirmation how the school context facilitates racial/ethnic identity among Mexican American adolescents. Hispanic Journal 
of Behavioral Sciences, 31, 5-31).

Graham, H. \& Hudley, C. (2005). Race and ethnicity in the study of motivation and competence. n Elliot, A. J. \& Dweck, C. S., Handbook of Competence and Motivation (392-413). New York: The Guilford Press.

Gregory, A., Skiba, R. J., \& Noguera, P. A. (2010). The achievement gap and the discipline gap: Two sides of the same coin? Educational Researcher, 39, 59-68.

Gutman, L. \& Midgley, C. (2000). The role of protective factors in supporting the academic achievement of poor African-American students during the middle school transition. Journal of Youth and Adolescence, 29, 223-247.

Hughes, D. Witherspoon, D, Rivas-Drake, D. \& West-Bey, N. (2009). Received ethnicracial socialization messages and youths’ academic and behavioral outcomes: Examining the mediating role of ethnic identity and self-esteem. Cultural Diversity and Ethnic Minority Psychology, 15, 112-124.

Kelly, S. (2008). Race, social class, and student engagement in middle school English classrooms. Social Science Research, 37, 434-448.

Lanza, H. \& Taylor, R. (2010). Parenting in moderation: Family routine moderates and relation between school disengagement and delinquent behaviors among African American adolescents. Cultural Diversity and Ethnic Minority Psychology, 16, 540-547.

Lowery, B.S. \& Wout, D.A. (2010). When inequality matters: The effect of inequality frames on academic engagement. Journal of Personality and Social Psychology, 98, 956-966.

McKinsey \& Company (2009). Detailed findings on the economic impact of the 
achievement gap in American's schools. Retrieved from

References 96

http://mckinseyonsociety.com/downloads/reports/Education/detailed_achievement _gap_findings.pdf

Miller-Jones, D. (1989). Culture and testing. In B. Rogoff (Ed.), Culture and

Development. American Psychologist, 44 (2), 360-366.

Miller-Jones, D. (1990). Informal reasoning in inner-city children. In J. Voss, D. Perkins, \& J. Segal (Eds.). Informal Reasoning in Education (pp. 107-130). Hillsdale, NJ: Lawrence Erlbaum Associates.

Mireles-Rios, R. \& Romo, L. (2010). Maternal and teacher interaction and student engagement in math and reading among Mexican American girls from a rural community. Hispanic Journal of Behavioral Sciences, 32, 456-469.

Ozer, E., Wolf, J., \& Kong, C. (2008). Sources of perceived school connection among ethnically diverse urban adolescents. Journal of Adolescent Research, 23, 438470.

Pierson, L., \& Connell, J. (1992). Effect of grade retention on self-system processes, school engagement, and academic performance. Journal of Educational Psychology, 84, 300-307).

Sciarra, D., \& Seirup, H. (2008). The multidimensionality of school engagement and math achievement among racial groups. Professional School Counseling, 11, 218228.

Sirin, S. \& Rogers-Sirin, L. (2004). Exploring school engagement of middle-class African-American adolescents. Youth Society, 35, 323-340.

Sirin, S. \& Rogers-Sirin, L. (2005). Components of school engagement among African- 
American adolescents. Applied Developmental Science, 9, 5-13.

Skinner, E. A., \& Belmont, M. J. (1993). Motivation in the classroom: Reciprocal effects of teacher behavior and student engagement across the school year. Journal of Educational Psychology, 85, 571-581.

Skinner, E., Wellborn, J., \& Connell, J. (1990). What it takes to do well in school and whether I've got it: A process model of perceived control and children’s engagement and achievement in school. Journal of Educational Psychology, 82, 22-32.

Skinner, E., Kindermann, T., Connell, J., Wellborn, J. (2009). Engagement and disaffection as organizational constructs in the dynamic of motivational development. In Wenzel, K. \& Wigfield, A. (Eds.). Handbook of motivation at school (pp. 223-245). New York, NY: Routledge/Taylor \& Francis Group.

Skinner, E., Kindermann, T., \& Furrer, C. (2009). A motivational perspective on engagement and disaffection: Conceptualization and assessment of children behavioral and emotional participation in academic activities in the classroom. Educational and Psychological Measurement, 69, 493-525.

Skinner, E. \& Pitzer, J. (in press). Developmental dynamics of student engagement, coping and everyday resilience.

Smalls, C. (2010). Effects of mother's racial socialization and relationship quality on African American youth’s school engagement: A profile approach. Cultural Diversity and Ethnic Minority Psychology, 16, 476-484.

Smerdon, B. (1999). Engagement and achievement: Differences between AfricanAmerican and White high school students. Research in Sociology of Education 
and Socialization, 12, 103-134.

Suarez-Orozco, C., Gaytan, F., Bang, H., Pakes, J., Connor, E., \& Rhodes, J. (2010). Academic trajectories of newcomer immigrant youth. Developmental Psychology, 46, 602-618.

van den Bergh, L., Denessen, E., Hornsta, L., Voeten, M., Holland, R.W. (2010). The implicit prejudice attitudes of teachers: Relations to teacher expectations and the ethnic achievement gap. American Educational Research Journal, 47, 497-527.

Wang, M., \& Holcombe, R., (2010). Adolescents’ perceptions of school environment, engagement, and academic achievement in middle school. American Educational Research Journal, 47, 633-662.

Wooley, M., \& Bowen, G. (2007). In the context of risk: Supportive adults and the school engagement of middle school students. Family Relations, 56, 92-104. 